\title{
Patient Education Using the Cognitive Apprenticeship Model: A Study for Rehabilitation Specialists
}

Paul M. Dye

University of St. Augustine for Health Sciences

DOI: https://doi.org/10.46409/sr.HVUJ4904

Follow this and additional works at: https://soar.usa.edu/dissertations

Part of the Rehabilitation and Therapy Commons

\section{Recommended Citation}

Dye, P. M. (2017). Patient Education Using the Cognitive Apprenticeship Model: A Study for Rehabilitation Specialists. [Doctoral project, University of St Augustine for Health Sciences]. SOAR @ USA: Student Dissertations Collection. https://doi.org/10.46409/sr.HVUJ4904 
Patient Education Using the Cognitive Apprenticeship Model:

A Study for Rehabilitation Specialists

\section{By}

Paul M. Dye

MPT., MOTR/L., ATC., CSCS

BS-Brigham Young University

MOT- University of St. Augustine for Health Sciences

MPT- University of St. Augustine for Health Sciences

Submitted in Partial Fulfillment of the Requirements for the degree Doctor of Health Sciences University of St. Augustine for Health Sciences 
September 2017

\section{Acknowledgements:}

First and foremost, I would not be at this stage without the support of my wife and children. Their sacrifice has made completion of this monumental task possible. My dear wife has sacrificed her time, hobbies, and energy in a selfless way to assist me on this journey. I am indebted to my brother, Alan Dye for convincing me to finish when I was ready to let go of it all. I must express gratitude for my parents, particularly my mother who always wanted to have a Dr.

in the family. I am grateful for the hours of assistance from professors, teachers, and friends who have urged me along the pathway. Specifically, Dr. Karen Howell, Dr. Matthew Whoolery, Dr. Dan Lofald, and Dr. Cindy Mathena have been critical to the completion of this project. In addition, I appreciate the therapists and staff at Rexburg and St. Anthony Rehabilitation and all the patients whom I have had the opportunity to treat, care for and work with, who have made this opportunity possible by choosing to seek care with our company. 


\begin{abstract}
Quality patient education has long been a concern for both patients and health care providers. While many clinicians support the importance of patient education, it is not known which theoretical education model supports best practice. The purpose of this study is to determine the effectiveness of the Cognitive Apprenticeship Model (CA) when compared to traditional patient education. There were 34 individuals receiving therapy who volunteered to be in a treatment group that received patient education using the CA model. There were 24 individuals who were assigned to a control group who received traditional patient education.

While not all of the outcomes measured in this study showed significance as anticipated, several key outcomes showed statistical significances between the treatment group and the control group. Thus, supporting the hypotheses that the use of CA in patient education would improve patient outcomes, specifically in 1) Patient Specific function analysis outcomes questionnaire. 2) Pre-test vs post-test scores on patient's knowledge about their condition and how to manage it. 3) Patient continued use of a home exercise program post discharge.

This is important in that the use of CA as a theoretical educational model for patient education resulted in better patient compliance with home exercises four weeks after discharge from skilled therapy. Greater differences in pre-test vs post-test knowledge scores, indicating patient empowerment and greater understanding of the importance of their continued follow-up to care for themselves. This supports the concept that the teaching methods used in how patients are taught is relevant and equally important to what they are taught. As healthcare providers learn to become better teachers of their patients, engaging in the use of theoretically grounded teaching methods, patient outcomes are likely to improve. This results in best practice methods for the delivery of healthcare and improvements in patient outcomes.
\end{abstract}




\section{TABLE OF CONTENTS}

Acknowledgements .............................. 2

Abstract ......................................... 3

Table of Contents ................................ 4

Chapter One: Introduction ............................ 5

Background

Statement of the Problem

Purpose of the Study

Rationale

Significance of the Study

Chapter Two: Literature Review .................... 11

Chapter Three: Methodology ........................ 43

Research Questions

Hypothesis

Variables and subjects

Inclusion/exclusion criteria

Methods

Ethical Considerations

Statistical Methods and Analysis

Standard Assessments and Measures used

Testing Threats

Chapter Four: Results

Measures

Statistical Process

Descriptive Statistics

Within-Subject Variability

Hypotheses

Chapter Five: Discussion

Summary and Conclusions

Study Limitations

Discussion

Recommendations

Future Studies

Appendices .................................... 80

References ...................................... 95 


\section{Chapter One}

Introduction and background to the Problem: One of the major components of patient care is education that informs a patient about their condition, prognosis, and how they can affect their treatment by how well they comply with instructions provided by their health care provider. The World Health Organization (WHO) described therapeutic patient education as "designed to train patients in the skills of self-managing or adapting treatment to their particular chronic disease, and in coping processes and skills. It should also contribute to reducing the cost of longterm care to patients and to society. It is essential to the efficient self-management and to the quality of care of all long-term diseases or conditions, though acutely ill patients should not be excluded from its benefits" (World Health Organization, 1998, p.5). Bartlett also defined patient education as "a planned learning experience using a combination of methods such as teaching, counseling and behavior modification techniques which influence patients' knowledge and health behavior" (Bartlett, 1985, p.323). For rehabilitation specialists like physical and occupational therapists, home exercise instruction and patient education has been identified as an essential component for successful treatment of patients.

Because informed patients are so important, patient education is mandated and advocated by professional practice in physical therapy (APTA, 2001; APTA, 2013). Patient education instruction is also required for academic preparation of physical therapy students (Commission on Accreditation in Physical Therapy Education, 2014). However, many physical therapists feel unprepared to provide education in a formal way, due to fears and lack of training. How to provide patient education has received inadequate attention by education programs. (May, 1983; (Pignataro \& Huddleston, 2015). This gap in provider training has been compounded by the lack 
of research in patient education for physical therapy practice as noted by recent investigations into professional literature. (Chase, Elkins, Readinger \& Shepard, 1993; Rindflesch, 2009). While patient education has been shown to be beneficial in improving patient conditions and overall outcomes, there is still a gap in the best methods to provide the education effectively. (Slujis, 1991; Pignataro \& Huddleston, 2015; Jay, 2010; May, 2001; World, 1998; Assal, Albeanu, Peter-Reisch \& Vaucher, (1993).

Background of the Study: Teaching and learning techniques have been studied for many decades to understand and improve human learning. Many theories and models have been introduced, studied, and provided advancements in teaching instruction. While no specific model has proven to be perfect, the cognitive apprenticeship model (CA) has been shown to be extremely effective for healthcare education (Lasley, 2016; Stalmeijer, 2015).

In 1987, a new teaching method appeared on the educational scene, using six methods of instruction developed by Collins, Brown, and Newman called "Cognitive Apprenticeship" and referred to as the Cognitive Apprenticeship Model (CA). CA lies deeply within the social constructional learning theories, and is grounded in theory and application that has been used for many years. In effect, it is based on the observation that individuals learn from a master and emphasizes modeling, imitation and observation (Collins, 2016). The six methods include: modeling, coaching, scaffolding, articulation, reflection and exploration.

Since the inception of CA, it has been used as a learning model in a variety of circumstances and has documented success as a method of instruction. CA was recommended for professional educators when learners need a form of instruction that is more effective than selfdirected learning (Farmer, Buckmaster \& LeGrand, 1992). CA also recommended to improve problem solving skills (Brand-Gruwel, 2004) (Nochol \& Turner-Bisset (2006) concluded that 
cognitive apprenticeship facilitates the transfer of teaching expertise (p. 167). Daley, Menke, Kirkpatrick \& Sheets, (2008) used principles from CA to train nurses in a large baccalaureate program. CA is a useful model for teaching strategies to medical undergraduate students and for faculty development (Stalmeijer, Dolmas, Wolfhagen \& Scherpbier, 2009). CA methods were used to teach psychiatric rehabilitation providers (Bates, Waynor \& Dolce, 2012). CA was used for radiation therapy instructors to teach new treatment setups to students (Lasley, 2016). A study by Backus \& Gulick (2016) concluded that CA is useful for accelerated leadership development and "the flexibility of the cognitive apprenticeship method can accommodate a diverse range of learning environments, integrate a variety of technologies and coaching solutions, and may be especially useful for developing individual's capacity to solve complex problems within a brief time frame.” (p. 146).

While CA has been applied by design in classrooms, universities, teaching hospitals, and other fields of study in a teacher-student relationship, the use of CA has limited documented practice in the provider-patient relationship. There is a significant gap in the literature studying the use of CA as a guided model for patient education and instruction (Collins, Brown, \& Newman, 1987).

Statement of the problem: Patient education has long been a concern for patients and physical therapists alike. While patient education has been extensively studied, the use of specific theoretical models in application to patient education lacks definition. Many clinicians will readily identify that patient education is important but there is a learning and knowledge gap between presented information and the skill of doing what is taught (Skelton, Murphy, Murphy \& Dowd, 1995), that clinicians do not feel adequately prepared to fulfill the role of patient educator (Pignataro \& Huddleston, 2015) and "therapists agreed that they were not adequately 
prepared in teaching skills" (Chase, 1993, p.788) and "a majority of practicing therapists do not feel adequately prepared in teaching skills by their basic training and are interested in learning more about teaching” (Sotosky, 1984, p.349).

Typical therapists will take a moment to explain to the patient their evaluative findings and provide some information regarding the patient's diagnosis, prognosis, and expected outcomes including a general timeframe. Therapists may give the patient a pictorial guide of the exercises they want the patient to perform and specify a quantity of sets to be performed. They may demonstrate to the patient what the exercise looks like and have the patient perform the exercise a time or two in the clinic before sending them home to work on these activities. However, this type of informational strategy is less effective than behavioral strategy because an increase in knowledge alone is not sufficient to ensure behavior change (Bartlett, 1982).

In a day where the internet is such an easy tool for patients to go and gather information, or in many cases misinformation, concerning their ailments it is imperative that the rehabilitation specialist be a strong reliable resource for the patient to turn for education and ask questions. The patient will know what to expect as they progress in their therapy regime. This will improve the provider-patient trust relationship and create an environment that patients can openly communicate with their therapist when things do or do not go as planned. The therapist must also be prepared to address the concerns and specific obstacles that challenge a patient from being compliant. Patients claim that it is not prevention knowledge they need but how to apply this knowledge in a difficult situation (Skelton et al, 1995).

In physical and occupational therapy, it is essential that good teaching methods be used when providing patient instruction and education. It is anticipated that patient education with CA will improve patient outcomes, empower patients to take charge of their healthcare, and increase 
patient satisfaction. There is a lack of the skills of pedagogy being sufficiently applied to maximize patient learning and successful outcomes. With patient education being a key component to successful therapy intervention, it is vital to apply an educational learning theory to patient education.

Purpose of the Study: The primary purpose of this study was to investigate the use of a specific theoretically grounded teaching method. In this study, CA was applied in a consistent manner across the clinical experience of patients with a variety of diagnoses during patient rehabilitation. The hypothesis was that consistent teaching, by specific design, makes a difference in patient outcomes.

Rationale: The rationale was that by knowing how individuals learn and using guided methods of instruction, greater learning can occur, not only through education but through transformational change as the individual empowers themselves with greater control over their own health and well-being. By giving the patient increased knowledge, understanding, and skill the patient would show increased intrinsic motivation to care for themselves and knowledge to be successful in self-care. Patients would recover more quickly that national norms and this could reduce the cost of healthcare.

Significance of the Study: Knowing how individuals learn and using a grounded method of instruction for patient education, like CA, improves learning. The learning goal was a behavioral, transformational change to empower patients to have greater control over their own health and increase their motivation for compliance and satisfaction with the process. Patients should recover more quickly and stay healthier which would potentially reduce health costs.

The significance of the study was to: (1) add to evidenced based research on patient education that will aid in establishing best practices; (2) influence the curriculum of health care 
professionals at the graduate level by encouraging increased content related to patient education using CA approach and adding this content to post-graduate continuing education; (3) improve healthcare practitioners confidence to successfully provide meaningful patient education; (4) improve patient outcomes; (5) document patient improvements that could lead to changes in reimbursement for patient education; and (6) empower patients with knowledge, skills, and motivation to participate in their healthcare, potentially reducing the costs to them and society.

The specific aims of the study were to indicate that patient education using CA will show efficacy resulting in improved patient outcomes, long term compliance, changed patient attitudes, knowledge, and behaviors. We anticipated the post tests and physical assessment scores in the CA treatment group would be higher than the control group. We anticipated that patients in the CA group would show more compliance at the 4-week follow up phone call in their home exercise program. We anticipated that patient satisfaction would be significantly higher in the group that received the CA approach to patient education. 


\section{Chapter Two}

\section{Review of the Literature}

To grasp the breadth and depth of information that is relevant to this topic, the literature was researched using Google Scholar, general internet searches, Search USA, and EBSCOhost publishing including unpublished dissertation research. The following is a review of the literature.

Overview: How people learn has been a subject of research for centuries. There are three basic types of learning theories; behaviorist, cognitive constructivist, and social constructivist. Some modern concepts include: Vygotsky and his social learning theory development; Bruner, Wood, Ross, and colleagues identify scaffolding as a primary component of educational theory; Bandura and social cognitive theory development; and finally, Cognitive Apprenticeship introduced by Collins, Brown, and Newman. Cognitive Apprenticeship (CA) has been used in various disciplines and formats including healthcare. Patient education is the process of teaching a patient about their condition, restrictions, adaptations and the processes of recovery. CA is a logical choice to use as the format for patient education in the clinical practice of physical therapy.

Vygotsky: Zone of Proximal Development (ZPD): During the early transition into constructivism from behaviorism as the foundational theoretical framework of educational practice, prominent psychologist Lev Vygotsky originated the concept of the social development theory which came to be known as the zone of proximal development (Vygotsky, 1956, 1978). The Zone of Proximal Development (ZPD) was originally developed to account for the learning 
potential of children (Shabani, Khatib, \& Ebadi, 2010). Vygotsky examined the effects of our social environments and their influence in particular on learning.

In the field of education, teachers are aware of the contributions of Vygotsky and how the ZPD works. For those, however, in fields of rehabilitation ZPD may be a new concept. Vygotsky defined this zone as "the distance between the actual development level as determined by independent problem solving and the level of potential development as determined through problem solving under adult guidance or in collaboration with a more capable peer" (Vygotsky 1978, p.86).

A simple explanation of the ZPD is to establish the lower end of knowledge or skill which is defined by the area where the learner can achieve knowledge through their own independent work. Then, establish the upper end of the zone which is where the learner combined with an expert or more abled learner can achieve through their potential work together. This combined area is the ZPD. The goal in learning is to work in this combined area but not at the lower level. It is important to spend time assessing where the learner is and push them towards the upper end of the zone for success in learning (Lofald, 2013).

The idea is that people learn better when they combine their knowledge with the knowledge or skill of others in a process of collaboration. After working with another in successful completion of a learned task that individual would be more likely to be able to perform that task independently the next time they attempted the task or skill (Roosevelt, 2008). Scaffolding: Jerome Bruner was an educational psychologist whose work was similar and built upon the work of Vygotsky. His theory is a more abled individual assists another learner in a task where the assistance could be increased or decreased dependent upon the learners' acquisition of the new skill. The process of creating assistance for the learner took hold and Bruner along with 
Wood, Ross, and other colleagues coined the term "scaffolding" based upon the construction term that describes the process of building a support structure around the building as its height grows to complete the structure. This same concept was applied by Bruner and colleagues in their work titled the "Process of Education" (Bruner, 1976). Both Vygotsky and Bruner keyed in on the use of language as the primary tool of social instruction and the importance symbols and language played in the learning skills of children (Wood, Bruner, \& Ross, 1976; Vygotsky, 1956).

Scaffolding as a learning method and viable tool for use in a variety of settings has expanded immensely. The use of scaffolding has been included in several academic fields and across all ages and cultures. Educators who design curriculums have found that although creation of scaffolding experiences may be time and labor intensive it is immensely rewarding as it produces consistent and positive results. One of the better examples of the use of scaffolding comes from reciprocal teaching by Palincsar and Brown (1984). They claim expert scaffolding helped students with learning strategies in an interactive environment where teachers and students took turns in the role of teacher using self-directed summarizing, questioning, clarifying, and predicting as guiding principles for learning and teaching. Having a teacher who understands what they are teaching at a level that is deep and significant is important for the teacher to be comfortable assuming this role. The teacher should keep a continual eye on the student to accurately assess where they are in learning the material that is presented. "The successful teacher must continually engage in on-line diagnosis of student understanding" (Brown, Ash, Rutherford, Nahaguwa, and Capione, 1993, p. 207).

In a study by Beed, Hawkins, and Roller (1991), the authors looked at the various responses of teachers during their interactions with children during reading. They suggested a 
progression of teacher responses that will eventually result in independence. The study identified two types of scaffolding; incidental (not consciously teaching the children) and strategic (more focused problem solving). In their study, the authors describe four essential features of scaffolding. These features include: interaction takes place in a collaborative content, operates in the zone of proximal development, implements a gradual withdrawal of support, and the child internalizes the knowledge in order to become an independent reader. Beed and colleagues (1991) proposed that teachers should use a contingent scaffolding which adds a pattern of responses to the typical scaffolding instruction. They adapted the description of Wood, Wood and Middleton (1978) of levels of responses to create a pattern a teacher could follow from Level E, the least independent, where the teacher assumes all the responsibility to Level A in which the student assumes most of the responsibility to perform the strategy independently and no longer needs cuing. The details of the study instructed a child to use a strategic word attack technique (SWAT). The five steps are read, reread with pictures, ask the child what word that starts with this letter would make sense in this sentence, look at other parts of the word, and read then ask for help. At Level E the teacher models a complete SWAT performance with accompanying explanations. Level D a teacher invites student performance or modeling with verbal explanations accompanied by some student explanations. Level C includes cuing specific elements and identifying the elements as the student completes them. Level B is cuing specific strategies without reference to the elements. Finally, at Level A the teacher provides general verbal cues and the least amount of support or scaffolding as possible. They observed the application of contingent scaffolding in multiple instructional situations including between an advisor and an advisee, in apprenticeship settings, training, tutoring, and between teachers and groups. The study clarified that group interaction is an interaction with the individuals of that 
group. This research provides insight into some of the key components of scaffolding and its use in early child education for reading.

Another example of scaffolding in education is found in the work of Jumaat and Tasir (2014) in a meta-analysis of instructional scaffolding in the online learning environment. Instructional scaffolding is teaching a student new skill by systematically building on their experience and knowledge. As technology extends learning beyond the classroom, there is a growing interest in the types of scaffolding that can work in the online learning environment. The analyzed articles on web based and software based tools like wikis, blogs, social networking sites, 3D animation cartoons or avatars. Four types of online scaffolding were identified; conceptual scaffolding; procedural scaffolding; strategic scaffolding; and metacognitive scaffolding. Conceptual scaffolding "helps students to decide what to consider in learning." (Jumaat \& Tasir, 2014, p.75). It particularly guides them to prioritize fundamental concepts. Procedural scaffolding assists students in using available tools and resources while strategic scaffolding suggests alternative ways to tackle problems in learning. Finally, meta-cognitive scaffolding guides students on "what to think during learning" (p.76). They determined that meta-cognitive scaffolding is the method that most appropriately supports student learning in the online environment because it promotes higher order thinking, assists students to reflect on their progress, and encourages students to plan ahead. The meta-analysis concluded with recommendations that teachers map out the following: student's need, learning objectives, support forms, and types of scaffolding appropriate to student's needs. In addition, they suggested that questions and prompt messages from the instructor be carefully designed to deliver the scaffolding effectively. Their observations noted that technology plays an important role in scaffolded learning and teachers should utilize technological tools that are available to 
support their teaching.

In Pea's discussion about scaffolding (2004), he points out that the learning was neither formal, designed nor computer generated but was naturally occurring in an informal context. Pea described two axes for organizing the theoretical contributions to support the processes of learning. One axis is social scaffolding, a concern for social interacting that is contingent on the needs of the learner and the other axis is technological scaffolding which is about designed artifacts like books, software, materials for learning and computer tools (Pea, 2004). Pea uses the definition provided by Collins, Brown, and Newman (1989) that the "fading" aspect of scaffolding requires that "once the learner has a grasp of the target skill, the master reduces or fades his participation" (Collins, Brown, Newman, 1989, p. 456). Pea clarified that without the dismantling mechanism of fading the support is then termed "distributed intelligence", a more pervasive form of cognitive support. He argues that the term of scaffolding is being misused in four contemporary research articles he reviewed. This can often be the case where once a term is coined others attempt to expand it and then redefine the term often differently giving the term a different meaning from its original intended form. For example, a teacher teaching a whole class a math principle then going back to their desk and waiting for students to ask for help would not follow the original definition or intent of scaffolding.

In another research article by Reiser (2009) the concept of scaffolding in the application of software development is discussed. He promotes two reasons for using software tools. First, software tools can help structure the learning task, guide learners through key components and support their planning and performance. Second, tools can shape student's performance and understanding of the task in terms of key content and strategies. He implies that software functions as scaffolding when it changes the task in some way so that learners can accomplish 
tasks that would otherwise be out of their reach. This again is an expanded definition of the original intent of the definition of scaffolding, as it doesn't really include social interaction. However, Reiser contends that tools such as software can change the nature of the task by limiting the part of the task that the learners need to perform. This change potentially enables learners to focus on more productive parts of the task. For example, calculators and word processors perform repetitive and complex functions and free up the learner to attend to new concepts more effectively. Tools are a critical factor in accessing, manipulating, storing, and reasoning about information (Norman, 1991). Norman describes tools that are used to represent and manipulate information in some task as cognitive artifacts or as "distributed cognition" (Collins, 1991). He argues that we need to spend more time investigating how scaffolding can positively influence software, instructional design, education, and curriculum.

Puntambekar \& Hubscher (2005) observed the term scaffolding is currently being applied broadly to include support in technology tools, peer interactions, and discussions aimed at the entire class. This is a departure from the original concept of expert-novice learning by scaffolding when "instruction in the zone of proximal development then came to be viewed as taking the form of providing assistance (or scaffolding), enabling a child or a novice to solve a problem, carrying out a task or achieving a goal that he or she would not be able to achieve on his or her own" (p.2). The authors point out that now instead of one teacher working with each student, support is being provided in a paper or software tool or classroom activities that involve peer review instead of teacher facilitation. Although these tools share aspects of scaffolding, they are lacking critical elements of scaffolding. Based on the review, the authors make three specific suggestions that will help create technology that will assist with scaffolding in the classroom. Suggestions include to consider there are multiple zones of proximal development in the 
classroom when designing tools. Second, build fading into the whole environment rather than to each tool so that the tools themselves could be removed when the student does not need them. Finally, orchestrate the classroom environment so that all tools and agents play a support role. "Tools that provide static support, or passive scaffolds, contradict the essence of the scaffolding construct by overlooking the change from 'other' to self-regulation" (p.9). The environment of a classroom is much different from the one-on-one environment for the original scaffolding. In conclusion, "more research is required so that the support that is static and non-adaptive and can be changed to what can truly be described as scaffolding" (p.10).

A review of 66 research articles on scaffolding by van de Pol et al. (2010) scrutinized the three commonly held characteristics of scaffolding. These characteristics included contingency or responsiveness and tailored support, fading or gradual withdrawal of the teacher support over time, and transfer of responsibility when the student takes increased learner control. Some authors argue that the term scaffolding has been applied too broadly, these authors defined the term narrowly as face-to-face interactions particularly between teacher and student. The authors created a conceptual model of scaffolding and a framework for the analysis of scaffolding strategies for analyzing future research. They concluded that "the results of studies that were found on student's metacognitive and cognitive activities and their affect point largely in the same direction, ... that scaffolding is effective" (p. 286). Some suggestion for research included establishing a need for a reliable and valid measurement of scaffolding, determining student measures to provide a clear indication of whether the scaffolding was effective to start with or not, and considering both student and teacher behavior and their discourse contributions to scaffolding. They made an interesting point that "although the focus of the framework is on teacher actions, it was noted that these cannot be accurately coded without consideration for 
student responses" ( $\mathrm{p}$ 286). They concluded that, much more research is needed on the processes of internalization and appropriation, as it applies to scaffolding.

Social Cognitive Theory Development: Scaffolding is at the very root of modern educational theory and has broad application in in classrooms and teaching scenarios. Bandura, one of the greatest modern learning theorists, used social cognitive theory to explain how individuals interact with their environments. He posits that humans are agents that operate within their environment and that we are proactive, self-reflective and self-organizing. As a contributing part of the social system we are also a result of our social environment (Bandura, 1999). Bandura explained that when modern computers came upon the scene, the concept of how humans think and learn also changed to the input-output model, then to an input-linear model, and then to a simultaneous multiple operation model. This new description of how the brain works explains how humans can think for themselves and make instantaneous decisions about what to do in their environment. When information is presented, humans use their sensory and motor systems to organize and make meaning of the data and interpret what they see, hear, and feel. By understanding how people learn, best practices can be applied to transfer knowledge from the expert to the novice.

History of Apprenticeship: Resnick (1987) points out that common sense or practical intelligence is different from school or formal intelligence and common sense is more important for success in the real world. "This wisdom is difficult to assess directly from a base of scholarly research" (Resnick, 1987, p. 13). He describes four broad contrasts between school learning and outside social learning. In school, individual cognition is assessed but out of school much activity is socially shared. A study by Hutchins (1987) of sailors working together on US Navy ships reported that every 1-3 minutes two people on deck took visual sightings using telescopic 
devices mounted on gyrocompasses. They called the readings to two other sailors who relayed them to the bridge. The specialist recorded and repeated the bearings for confirmation. No single person could navigate the ship with their singular knowledge. "The knowledge necessary for successful piloting is distributed throughout the whole system” (Resnick, 1987, p.13) which extends to the tools and the tool builders like the cartographers and the gyrocompass designers. The second contrast between school and outside learning is that in school the individual is typically encouraged to think on their own and solve problems without the aid of books, notes, and calculators. In contrast, "most mental activities outside school are engaged intimately with tools, and the resultant cognitive activity is shaped by the tools available" (Resnick, 1987, p. 13). The use of tools enables a person with limited education to have a greater capacity for accomplishment as they draw upon resources like a computer or software program to take them beyond their own ability. Another contrast is that school learning is mostly symbol based and outside learning typically involves contextualized reasoning. The last contrast is that learning in school is usually general so that it might be transferred to a variety of situations. Outside school learning is generally situation specific. Resnick (1987) suggests that current classrooms are inadequate in providing learning for the real world. Often in school, too much time is spent worrying about the book form of knowledge and not getting to the practical form. Her article suggests developing new forms of training for competent functioning in a variety of situations, reintroducing elements of the traditional apprenticeship, possibly using a "bridging apprenticeship" that simulates a work environment with social interactions.

Another example of the use of educational theory frameworks was a clinical teaching project in a nursing program called "Partners in Practice". This program pairs senior nursing students in a leadership course with instructor-led groups of first year nursing students. The 
program was designed to focus on the mutual learning needs of two different levels of students. The study by Daley, Kirkpatrick, and Sheets (2008), incorporated three foundational learning frameworks including Piaget's (1985) cognitive development, Vygotsky’s (1978) zone of proximal development, and Mezirow's (1991) transformational learning. Piaget asserted that cooperation among peers was essential for learning. Vygotsky maintained that social interaction and collaboration with peers is essential in developing higher level behavioral and cognitive skills. Mezirow described in the transformative learning theory that learning is best retained through social interaction. The results showed that patients were pleased to experience a student partnership and senior students were less task oriented and more focused on the scope of responsibility associated with the role of leader. Nursing students were initially worried about gaining the necessary experience required for the national licensure examination, but upon completion of the program, they were positive that the role of practice partner helped them realize leadership and management skills. Unexpected benefits reported by the faculty for the first-year students were the ability to assign higher acuity patients to the student partners.

Task Centered Learning or (TCL) promotes a way of learning real world problems that connect with school learning so it can be applied in out-of-school situations. Francom \& Gardner (2014) compared four models that have influenced task-centered learning; One model was Cognitive Apprenticeship model proposed by Collins, Brown, and Newman (1989). The four models were compared and combined to explore common prescriptions for TCL in five main areas; learning tasks, activation of prior knowledge, demonstration/modeling, application, and integration/ exploration. The suggestion was that an approach to teaching and learning is more in line with TCL principles when it incorporates more of the prescriptions in the five areas and an approach to teaching is less in line with TCL principles when it incorporates fewer prescriptions. 
They concluded that, "using the essential components of TCL can be a viable way to provide meaningful learning, enabling students to function more effectively in the real world" (p. 36).

Additional models such as Authentic Apprenticeship for teaching evidence based practice have been explored, particularly in the field of physical therapy education. Miner (2007) found that there is limited research for teaching evidence-based practice (EBP) to allied health students. His doctoral dissertation research project addressed two questions: (1) How do physical therapy (PT) educators teach their students to analyze current research studies and incorporate their finding into patient plans; (2) What recommendations can be incorporated into an educational model for the field of physical therapy? He interviewed 31 educators from professional PT programs regarding current methods of teaching EBP. He found that most educators of physical therapy students in his sample used an Authentic Apprenticeship Model based upon the theories of authentic learning and cognitive apprenticeship. The Authentic Apprenticeship Model is an additional model for patient education.

Motivational interviewing (MI) was a concept developed by William Miller in the 1980's to combat alcohol and drug abuse. It is now being used by counselors and therapists to improve motivation for a variety of issues including exercise and healthy eating habits. The concept includes three elements. First, therapists can elicit change talk from the client. Second, therapists can empower clients to overcome ambivalence. "By understanding where the client is along a motivational continuum and helping the client gain related insight, the therapist can then tailor sessions accordingly, such that the client is optimally challenged" (Froiland, 2016, p. 2). Third, in order to be successful, therapists should be highly trained in MI before they conduct it. Miller, the originator of MI, suggested that rather than trying to convince clients to change, counselors would be more effective if they elicited arguments for change from the clients themselves. 
Emmons \& Rollnick, (2001) referred to MI as an empathetic therapeutic style. MI contains five guiding principles; (1) Express empathy by use of reflective listening; (2) develop discrepancy between client goals and current problem behavior with objective feedback; (3) avoid argumentation by assuming the client is responsible for the decision to change; (4) roll with resistance rather than confronting or opposing it; (5) support self-efficacy and optimism for change. MI is different from traditional health education because it places the client in the role of expert. Readiness to change is particularly important to the effectiveness of MI. "If the practitioner assumes that the client has greater readiness to change than he or she actually has, resistance will be a predictable outcome" (Emmons \& Rollnick 2001, p.70). Because MI is more effective with more contact time, physical therapists are in an ideal position to use this tool to increase the motivation of clients to make changes. "Repeated contact may be required in order to initiate the behavior change process, to shape new behaviors, and to provide the ongoing support central to behavior change" (Emmons \& Rollnick 2001, p.71).

These models have been useful but have not followed educational theory and learning models closely so Cognitive Apprenticeship as a model for patient education is relevant.

Development of Cognitive Apprenticeship: Collins, Brown, and Newman (1987) originally proposed Cognitive Apprenticeship (CA) as a method to teach students problemsolving skills in school subjects such as reading, writing, and mathematics. The authors reminded educators that before schools, apprenticeship was the most common means of learning and was used to transmit knowledge and skills for expert practice in fields of painting, sculpting, medicine, and law because it "embeds the learning of skills and knowledge in the social and functional context of their use" (Collins, Brown, \& Newman, 1987, p.3). Collins et al. (1987) described the apprenticeship as: 
(1) Modeling

(2) Coaching

(3) Fading

In the modeling step, the apprentice repeatedly observes the master executing or modeling the target process. Step two, the apprentice attempts to execute the process with guidance and help from the master. Finally, the master reduces his participation (fading) and provides only limited feedback to the learner. The authors propose two methods for developing self-monitoring and correction skills. The methods are abstract replay and evaluative processes. Abstract replay is an "alternation between expert and novice efforts in a shared problem-solving context which sensitizes students to the details of expert performance as the basis for incremental adjustments in their own performance" (p.4). Generative and evaluative processes are developed by discussion and group problem-solving The study encouraged active learning, "to the degree the reader or listener is passive, they will not learn as much as they would by apprenticeship, because apprenticeship forces them to use their knowledge" (p. 5). The proposed framework for CA includes six steps:
(1) Modeling
(4) Articulation
(2) Coaching
(5) Reflection
(3) Scaffolding
(6) Exploration

Since the inception of CA, the framework they suggested has been used as a successful tool in countless arenas and teacher-learner interactions. The following articles reference ways in which the CA model has been applied in various educational and professional situations.

Bates, Dolce and Waynor (2012) propose the use of CA to teach staff complex skills particularly for therapists providing job development training for clients with serious mental 
illness. They assert that "learning takes place by observing and by participating with peers and more skilled experts" (Bates, Dolce and Waynor, 2012, p.7). The study recommends that rehabilitation practitioners use basic skills such as meeting employees and coordinating job interviews through role plays. The expert should coach, give feedback and help the client put these skills into practice. Although not a complete use of all the concepts of CA, the authors feel that the model does an excellent job of providing a working framework that is successful.

Two educational faculty members from Florida State University published a chapter titled "The Cognitive Apprenticeship Model in Educational Practice" (Dennen \& Burner, 2008). They describe Apprenticeship as an ancient method of teaching. It is the process where a more experienced person assists another less experienced one, providing support and examples, so the less experienced person gains new skill knowledge and skills. Two examples they provide are of a parent teaching a child how to tie shoes and the process through which a person may learn to become a chef or a tailor. They identify apprenticeship closely with that of teaching in the ZPD where larger skills are broken into smaller ones and support is provided so that tasks are within the reach of the learner's current ability level or ZPD (Vygotsky, 1978).

In addition, the authors insist the tasks must represent authentic skills and not just classroom type exercises. Today, apprenticeship has been formalized into vocational education programs such as a journeyman electrician. The concept of Cognitive Apprenticeship defined by (Collins et al. 1989) is defined as "learning through guided experience on cognitive and metacognitive skills rather than physical skills and processes" (Collins et al.,1989, p.5). Slightly different apprenticeship versions have been proposed, but Collins, Brown and Newman's model is considered the foundational one. There are four concepts that pertain to the development of the CA literature: situatedness; or active learning that takes place in an authentic setting; legitimate 
peripheral participation that validates observation as a learning activity; guided participation which is a social element in the learners ZPD; and membership in a community of practice (Dennen \& Burner, 2008).

Jarvela (1995) analyzed 22 students, age 13-14 years, in a Finnish comprehensive school. The students took part in experimental lessons taught by an experienced researcher with a strong theoretical knowledge of CA and practical knowledge of Lego technology. The analysis by Jarvela supported the idea that learning interaction with CA can be supported by technology. "The most obvious advantage in the discussions between the teacher and the students was the reflective activity aided by the computer and the physical model constructed of Lego-bricks. With the help of the available technology, the cognitive work of the students was externalized and made jointly available in the interactions... and facilitated scaffolding discussions between the teacher and student" (Jarvela, 1995, p.256).

Stalmeijer, Dolman, Wolfhagen, and Scherpbier (2009) articulate that throughout history, the medical profession has used apprenticeships in the training of physicians. They also report that CA is not only a teaching method but its four dimensions are also relevant to medical learning environments and should be applied to the redesign of pre-clinical undergraduate classrooms and to the training of clinical supervisors (Stalmeijer, 2015). The author states "principles of apprenticeship have endured through the ages and are still used in various professions" and "cognitive apprenticeship builds on the strength of these principles and has potential to guide many more medical masters and their apprentices into the next millennium" (Stalmeijer, 2015, p.356).

Farmer and colleagues (1992) looked at the uses of cognitive apprenticeship in continuing professional education. They interviewed over 450 practitioners in five professions 
about the forms of instruction that they found most meaningful and helpful in learning to deal with ill-defined, complex and risky situations. Interviewees state that what helps most is "being taught by someone who models how to understand and deal with such situations and who then guides learners' attempts to do the real thing." (Farmer, Buckmaster, and LeGrand, 1992, p. 41). The authors suggest that biographical information could be used to match learners with teachers that would have the most benefit.

Cognitive apprenticeships adapted for continuing professional education should consist of five phases: (1) modeling a professional activity that the learner wants to be able to perform satisfactorily; (2) learners approximate doing the real thing while articulating the essence of their thoughts; (3) learners, individually or in groups, continue doing the real thing as coaching and scaffolding decrease; (4) internalizing so the learners can do the real thing on their own and assistance is only provided on request; (5) the final phase when the model and learner discuss the generalizability of what has been learned.

There are three crucial steps to implementing cognitive apprenticeship, selecting the situation, choosing the model to be used, and facilitating the experience. "The choice of an appropriate professional to do the modeling is important. Because learners learn best when they identify with the person instructing them, the models should be similar in age, cultural background, and outlook to the learners" (Farmer, Buckmaster, \& LeGrand, 1992, p. 45). When facilitating the experience, models and learners should be asked to think aloud while they perform. The authors suggested CA is an excellent way to teach continued professional education across multiple fields. Switching from traditional learning methods such as workshops and short courses can be insufficient for learning to understand or deal satisfactorily with complex situations. They advocate using CA particularly when learners need a form of 
instruction that is more effective and efficient than self-directed learning, when there is a low tolerance for error or risk, or learners have failed to learn adequately through other methods. The authors conclude that CA is successful because it "facilitates the development of appropriate learner schemas by embedding the learning of practical knowledge in its natural context and having models make explicit the knowledge and attitudes associated with their behavior" (p. 47).

CA while similar to Bandura's (1986) social learning theory expands in its application of how we learn by "providing an additional dimension of learning, resulting in a more enriched training experience" (Bates, Dolce, and Waynor, 2012, p. 9). The authors recommend training rehabilitation providers with cognitive apprenticeship methodologies and then evaluating the efficacy of CA approach using a baseline and post training practice/outcome measures.

Kirschner (1992) discusses the difference between practicing science and learning to practice science. He reports on the flaws that exist in the epistemology of the natural sciences. Kirschner posits that a major problem in science education is that practical work in conventional courses is poorly related to course objectives and consists of exercises for developing manipulation skills rather than problems in systematic thinking. He suggests three motives for using a practical to teach school science more effectively. These include that a practical is best suited for developing specific skills such as discrimination, observation, measurement, estimation, manipulation, planning, execution and interpretation. Educational simulations can be out-screen (where participants are placed in a role play, game or with physical scale models) or in-screen simulations where a computer plays an essential role. Teacher guidance, reflection and practice increase the student's meta-reasoning skills or the ability to plan their problem-solving approach as the result of experience. The second motive is a practical is a suitable vehicle for learning the academic approach to working as a scientist. This investigation process develops the 
skills of studying a situation, defining the problem, seeking alternative solutions, choosing best strategies, solving the problem, and evaluating the solution. Students need to discuss, reason and compare with other students. CA used successfully by Brown, Collins, and Drugid (1989) in teaching math, encouraged students to learn distinct types of knowledge through authentic practices and social interaction: mathematical knowledge; intuitive knowledge; computational knowledge; concrete knowledge and principles knowledge. Kirscher insists that modeling must be followed by group reflection. In a review of more than a thousand studies, Johnson and Johnson (1985a) reported that cooperative learning led to better learning results than either individual or competitive learning experiences. (Johnson \& Johnson, 1985a). The third motive to implement practical's to allow students to experience phenomena and gain tacit knowledge of a variety of scientific phenomena and their settings. Educators need to incorporate better teaching to create experiences thru scaffolding that will help the science learner become the science expert. The Kirschner (1992) study encourages the use of CA model for teaching to get the students into authentic practice and interaction. CA creates an additional tool set to enable learning to occur. When learners observe skilled individuals who already are proficient at a task, they became a better learner because they observed a demonstration of how to develop the skill. This approach is the modeling component of CA.

Additional studies and cognitive apprenticeship literature identify three types of apprenticeships as defined by Benner and Sutphen (2007) as:

(1) Cognitive or intellectual apprenticeship which includes conceptual training to learn the academic base.

(2) Skill-based apprenticeship of practice which includes the development of skilled know-how and clinical judgment 
(3) Apprenticeship to ethical standards, ethical compartment or behavioral, social roles and responsibilities of the profession

This third type of apprenticeship is referred to as civic professionalism in Noone's article about teaching (Noone, 2008). Noone reports on the integration of three apprenticeship types into professional nursing curriculum. She claims that identifying learning for professional nursing practice outcomes and then designing learning activities and experiences to meet those key practice elements can be adapted to a variety of curricular topics and program levels within nursing to prepare nursing students for practice.

The world we live in has access to unlimited information and knowledge. How does a student determine the validity and relevance of the information to a problem? Students must master the complex cognitive skill of information problem solving which includes; completion of tasks or assignments that require them to identify information needs, locating corresponding information sources, extracting and organize relevant information from each source, and synthesizing information from a variety of sources. This skill doesn't come naturally, it must be learned. A study by Brand-Gruwel, Wopereis, and Vermetten (2004) compared the information problem solving processes of experts and novices to create a detailed skill decomposition. The resulting decomposition includes five main skills and a regulation skill.

(1) Define the information problem. This includes defining well-formulated questions and sub questions, list of needed information, and clear task requirements.

(2) Search information. This requires internet skills, ability to derive the right search terms and judge the search results on validity, relevance and reliability.

(3) Scan information for quality and relevance and then elaborate on content.

(4) Process information. This includes reading, analyzing, selecting, structuring, 
comprehending and integrating the pieces of information. These steps are the analysis portion of the process.

(5) Organize and present information. This is the synthesis portion and refers to making the product as required in the task.

Sub skills of information organization are to formulate the problem, outline the problem, structure the product, formulate the text and elaborate on the content. Regulation takes place continuously while executing all five main skills.

The study by Brand-Gruwel et al. (2004) found that the biggest difference between the expert and novice group in information problem solving skills was the percentage of time spent in actually defining the problem. Results showed that experts when scanning spent more time on content in comparison to their novice counterparts. The experts also processed information more frequently. Experts spent more time formatting the actual problem. When given a time limit experts would take the entire time they were allotted and would have probably used more. The authors posited that one possible answer for these results was the prior knowledge that experts could use to process new information. In particular, the experts showed more monitoring and steering activities and oriented themselves more often to the time left to accomplish the task Brand-Gruwel et al concluded that a whole-task approach is recommended for teaching information problem-solving skills. Experts spent more time on the whole information problemsolving task, especially on the problem definition so students should be encouraged to take all the time they need in this area. To improve the skill of processing information, working together or collaborative problem-solving practice can stimulate elaboration and enhance student's understanding of the topic. For more success in the sub skills of judging quality, relevance and reliability, the authors support teacher input but also indicated that teachers themselves may be 
poorly equipped to access the world of information. Training for regulation problem solving skills requires students to constantly monitor and ask questions to find out if they are getting the actual information they need. The authors in this study highly recommend using Cognitive Apprenticeship (Collins, Brown \& Newman, 1989) as an approach to teach students. The study recommends demonstration, discussion, alternation of teacher and learner roles (reciprocal learning) and co-operative learning as techniques to help students internalize the processes of information problem solving. In addition, using scaffolding would help the, progress from novice to expert status.

Backus and Gulick (2010) found that the use of CA is being adopted by businesses for the purpose of leadership development. Their study explored the use of immersive learning as well as CA to accelerate leadership development. "Immersive learning strategies vary in type and method of delivery but are generally categorized into six areas: simulation; game-based learning, tabletop exercises; interactive stories; board games and alternative reality games" (Backus \& Gulick, 2010, p.145). They referred to the Collins et al., (1989) assessment that "CA complemented and reinforced the lessons learned in immersive learning because of the deliberate transfer of knowledge that occurs from the master to the apprentice using crucial support and feedback from the expert" (p.145). The authors go on to say, "overall the flexibility of CA can accommodate a diverse range of learning environments, integrate a variety of technologies and coaching solutions and may be especially useful for developing individuals' capacity to solve complex problems within a brief time frame" (Backus \& Gulick, 2010, p. 146). A key benefit is this solution typically works with existing organizational structures and current job-related tasks. An interesting observation was the suggestion to integrate virtual technology with CA to allow the master or senior leader to interact with an emerging leader through email, blogs, social 
networking sites, chats and blogs to promote learning even if the two individuals are not in the same office. They concluded that the use of CA combined with immersive learning in an accelerated leadership development program could "enable emerging leaders to develop faster and make significant contributions sooner... while making fewer demands on resources than conventional leadership training programs" (p.147).

In a study with three groups of 6th year medical students who were exposed to six teaching methods, Stalmeijer, Dolmans, Wolfhagen, and Scherpbier (2009) concluded that using the methods of CA along with a positive learning environment constituted a valuable learning experience. The students who volunteered for the study gave feedback on their clinical instructor's use of CA. The main problem reported by the students was 'the variability in the use of the teaching methods, which they regretted and attributed to clinical teachers not taking enough time for teaching or to lack of teaching skills" (p.9). The study pointed out three specific observations made by the volunteers:

(1) students may stimulate the use of certain teaching methods by their own proactive behavior

(2) some teaching methods require prolonged engagement in one discipline or with one individual teacher to reach a deeper level of engagement

(3) teachers should ascertain what level of learning or skill they have achieved in order to gear their instruction to the student's needs by asking in which year they were enrolled in and which rotations they had completed

Lasley (2016) identifies CA as a teaching model that is ideally suited for radiation therapy students who are learning mental skills that are difficult to demonstrate. "Cognitive apprenticeship is a model for teaching intellectual skills" (Lasley, 2016, p.103). This 
instructional approach teaches students to think about what they are learning and apply it to the next situation. She reminds the reader that CA is rooted in the social constructivist theory, "which encourages students to be actively involved in their learning" (p.103). The author concludes that the ability to learn throughout life is the key to CA and radiation therapy instructors must consider the interconnectedness of the many situations students will face and incorporate exercises into learning activities that challenge students to think broadly about what they're trying to accomplish. The use of CA "invites the radiation therapy instructor to teach new treatment set ups and to design students' clinical experiences based on complex thinking and reasoning skills involving thinking and reasoning, which form the cornerstone of high-quality patient care" (p.105).

A doctoral dissertation research abstract by Dunn (2014) from Northern Kentucky University incorporated CA in the coding and analysis of participant responses describing their field studies. Twelve occupational therapy students described their experience with an online discussion group. The results described student perceptions of (1) the fieldwork educator-student relationship, (2) the fieldwork educator's ability to adjust learning situations and provide prompt and direct feedback, and (3) appropriate learning situations which prompted the student's role change to clinician and the need for fieldwork educators to be leaders. Effective fieldwork educators could use CA to successfully help students progress to become professionals.

When it comes to teacher development and helping teachers become better at teaching, the use of CA has been identified as a positive way to accomplish this. This statement is supported by Nichol and Turner-Bisset (2006). who looked at teacher development of hundreds of teachers in the Nuffield Primary History Project (NPHP). The project implemented a program for the professional developments of teachers based on CA. The program was dispatched in five 
local education systems from 1998-2003 with 400 participating teachers and aimed to introduce the teachers to a wide range of classroom teaching strategies that were relevant to their own teaching using CA. The NPHP program focused on the first three steps of the five phases of CA developed at University of Exeter. These steps were demonstration of a teaching protocol by an expert teacher, teacher abstracted replay, reflection and mental -modelling of what the protocol involved, and teacher implementation of the underpinning principles, ideas, and teaching approaches, teacher reflection, and fading which includes autonomy. "CA provides a systematic, coherent, consistent, progressive and contextualized framework" (Nichol \& Turner-Bisset, 2006, p. 155). In conclusion, "The evidence from the NPHP course suggests that the CA pattern of professional development involving higher education course tutors enables teachers to assimilate and accommodate new teaching strategies and internalize them" (p.166).

The history and development of CA has been discussed. The literature review now specifically focuses on patient education and CA.

Patient Education: Since the dawn of healthcare it has been the role of the healthcare provider to help the patient understand what is going on with their body and to instruct or teach them what they can do to help fix their problems. In a study regarding patient satisfaction with back pain, explaining and teaching was described not as a "straightforward transmission of knowledge to passive recipients, but an active process in which the patients gain a greater understanding of their condition, and as a consequence manage it better" (May, 2001, p. 13). May (2001) further described patient education as a "consultative rather than a prescriptive process" (p.14).

In physical therapy, a common definition of patient education is "a planned experience using a combination of methods such as teaching, counseling and behavior modification 
techniques that influence patient's knowledge and health behavior" (Bartlett, 1982, p. 323).

Chase, Elkins, Readlinger, and Shepard (1993) determined that "how physical therapists teach is as important as what they teach" (p.59).

Sluijs et al. (1991) at Netherlands Institute of Primary Health Care developed a checklist of 65 educational activities to encourage and discover the extent of patient education provided by physical therapists in their clinical interactions with patients. The checklist they developed suggests three conditions and five elements for effective patient education: (1) Open and communicative atmosphere during the treatment; (2) Planned and systematic approach to the care given; (3) Concern for the patient's demands and perceptions. The five elements were:

1) teaching and informing about the illness

2) instructing the patient to perform home exercises

3) giving advice and information about illness-related behavior

4) giving general health education

5) counseling the patient about stress-related problems

Professional Mandates: The American Physical Therapy Association (APTA) Guide to Physical Therapist Practice (2001) states that physical therapists, "provide education to patients/clients" and are "involved in promoting health, wellness, and fitness initiatives, including education and service provision that stimulates the public to engage in healthy behaviors" (p.40).

The Commission on Accreditation in Physical Therapy Education (2014) describes criteria for the curriculum for Physical Therapist educational programs and refers to physical therapy skills in patient education with the following statements:

(1) The physical therapist professional curriculum includes content and learning 
experiences in teaching and learning (p.29).

(2) Effectively educate others using culturally appropriate teaching methods that are commensurate with the needs of the learner (p.33).

(3) Collaborate with patients/clients and family members to determine a plan of care that is acceptable, realistic, culturally competent, and patient centered (p.34).

APTA Vision Statement for the Physical Therapy Profession (2013) includes the encouragement for innovation in education that is "anticipating the changing way adults learn" and will "foster new educational models and delivery methods (p.1).

Benefits and Obstacles of Patient Education: The World Health Organization (WHO) published an extensive report (1998) to guide health care providers in providing patient education. The report asserts that patient education results in a decrease in admissions and financial savings but too few physicians educate their patients to manage their condition perhaps because of "too little time or lack of awareness of the need to do so" (World, 1998, p.4). The report indicates that the major obstacle to patient education is the lack of trained providers who have the training to provide effective patient education as well as a shortage of teachers to do the training. Assal, Albeanu, Peter-Riesch, and Vaucher (1993) claimed the real cost of the efficient control of a disease is the resistance from health care providers to implement patient education programs. In the same study, Assal et al. concluded "Therapeutic patient education has brought about a significant decrease in the number of hospital admissions of patients with bronchial asthma or diabetic coma. In addition to a decrease of lower limb amputations it has resulted in a better quality of life by delaying amputations in $75 \%$ of cases" (p.491-5).

Patient education is considered a basic skill in physical therapy, and $80 \%$ to $100 \%$ of physical therapists (PTs) surveyed routinely provide patient education. However, "a majority of 
practicing therapists did not feel adequately prepared in teaching skills by their school based training and interested in learning more about teaching" (Sotosky, 1984, p. 349). Historically, the training in school has not been sufficient to enable graduating therapists the confidence in their skills as teachers. In a nationwide study of PTs, 99\% felt that teaching was an important skill and $98 \%$ indicated that they participated in individual patient education, but only $34 \%$ had received instruction in teaching as part of their basic preparation (May, 1983). All of the PTs that were surveyed agreed that PTs play a key role in health promotion and illness prevention. However, 25\% were unaware of the Transtheoretical Model (TTM) of human behavior. TTM describes the stages of change, readiness to act on new healthier behaviors, and strategies for change and $10 \%$ were unaware of "The As" behavior intervention protocol inherent to motivational interviewing (MI). Motivational Interviewing is an approach that moves individuals from indecision to accomplishing goals and the A's are five major steps to intervention that are based on a patient's willingness to stop a behavior such as smoking by ask, advise, assess, assist, and arrange (Pignataro \& Huddleston, 2015).

Role of Physical Therapists: According to the updated APTA Guide to Physical Therapy Practice (2014), PTs should play a key role in the prevention of injury and disease, the promotion of health and wellness with patients and communities. "They provide education to patients/clients, students, facility staff, communities, and organizations and agencies" (APTA, 2014, p. 40). This statement implies that therapists must be both knowledgeable and capable as teachers for patients and the community. Teaching effectiveness will be determined by the ability of the physical therapist to provide education to these populations in a manner that is understandable and motivating. "Instruction may be related to the current condition; specific impairments, functional limitations, or disabilities; plan of care; need for enhanced performance; 
transition to a different role or setting; risk factors for developing a problem or dysfunction; or need for health, wellness, or fitness programs" (p. 47).

Morris, Kitchin, and Clark (2009) encourage PTs to expand their role in healthcare. "Health promotion, wellness, and prevention are critical areas of focus for physical therapists in meeting the expectations of consumers, communities, and societies across the globe. As experts in the management of movement dysfunction, physical therapists have the opportunity to integrate their expertise in movement dysfunction into the development and implementation of comprehensive management plans for patients/clients across the life span" (Morris, Kitchin \& Clark, 2009, p. 419).

According to Pignataro and Huddleston (2015), "PTs and physical therapy assistants (PTAs) have a moral obligation to address the current health care crisis by empowering the individuals to assume an active role in health promotion and wellness through changes in personal behaviors" (Pignataro \& Huddleston, 2015, p. 62). The authors go on to claim that PTs are uniquely positioned to teach patients with increased frequency of visits in the rehabilitation setting over a short period of time that includes regular follow-up and several teachable moments that can be used for motivation and learning. "Therefore, it is essential that PTs and PTAs possess not only the expertise to prescribe and administer the correct exercise, but the knowledge and skill to encourage individual motivation in establishing lifelong health habits known to reduce the risk of morbidity, disability, and premature mortality" (p.63).

The therapist has a vital role to provide information and work with patients to address their individual concerns, "not just to make particular episodes of care satisfactory, but in helping patients deal with their problem" (May, 2001, p. 18). Often the role of educator is relegated to the PT as often the physician reports not having sufficient time for patient education (Parsons, 
Harding, Breen, Foster, Pincus, Vogel \& Underwood, 2007). This relegation to a teaching role supports the trust placed in the therapist by a physician to ensure patients understand their condition, healing process, and necessary steps to be taken for successful outcomes.

Pignataro and Huddleston (2015) recommend two factors to achieve behavior change: readiness to change and belief in his or her capacity to engage in new behaviors. "By including an assessment of the patient's readiness to change as part of the initial patient interview and follow-up evaluations, the PT can determine the best approach for empowering patients in choosing healthy behaviors" (p. 63). The authors recommend an increased use of motivational interviewing (MI) in patient education and gathering data to evaluate the effectiveness of different types of patient education "PTs and PTAs must become more diligent in documenting details of patient education so that data will be available to evaluate various methods and results" (p.67).

A study by Hills and Kitchen (2005) interviewed patients who had recently completed outpatient therapy and found that patient satisfaction was determined by several categories that were important to patients that included: personal and professional manner, explanation/teaching during the episode, degree of consultation, access and time with therapist, and outcome. “Although patients did not always achieve symptom relief following treatment, they were generally satisfied with their care, particularly with the information they received with respect to self-management" (Hills \& Kitchen, 2005, p.3). According to the authors, patients appreciate being giving information and explanations because it increases their confidence and motivation. In this study, "patients valued a therapist who was empathetic, encouraging, knowledgeable, provided a good explanation of their problem, and enable them to develop self-management strategies and were dissatisfied when these were lacking” (p. 14). 
Emmons \& Rollnick (2001) described the challenge of developing a teaching model that is tailored to the individual patient and can be standardized and replicated to evaluate its efficacy. They determined five concepts that would lead to an effective teaching model for patients:

(1) Researchers must be familiar with the population being served.

(2) Pilot work with the target group is essential.

(3) Pilot work with target practitioners is also essential.

(4) Do a comprehensive evaluation to show evidence of skill acquisitions for staff.

(5) Consider what an appropriate outcome is.

Chase, Elkins, Readlinger, and Shepard (1993) suggested that further research on patient education would be helpful in the following areas: (1)what methods are the most effective in delivering a high quality of patient education and determining if they improved health behavior?, (2) determine which educational-behavioral strategies are most suitable to dealing with specific barriers to effective patient education., and (3) how does patient education differ in a variety of healthcare settings and based on clinical problem presented by the patient.

Chase et al. stated, "results from such studies could be incorporated into physical therapy curricula and continuing education courses, with the intent of improving patient teaching skills and thereby improving patient care" (Chase et al., 1993, p.794).

Justification and Conclusion: Research indicated that CA is a very effective framework for teaching students, businessmen, physicians, educators and health providers. A major component of successful patient outcomes is therapeutic patient education. Historically, there has been a gap in the training of healthcare professionals that gives them the foundational tools and confidence to provide effective patient education. CA was a logical learning model to choose for training therapy providers and for providing patient education to rehabilitation patients. After a 
review of the literature available, it was clear that there was limited information on using CA as the model for patient education in the physical therapy clinic.

The primary purpose of this study was to investigate the use of CA, a specifically theoretically grounded teaching method, for patient education with physical therapy patients about their condition, restrictions, treatment plan, and home exercise assignments. The hypothesis was that consistent patient education using CA would make a significant difference in patient outcomes. 


\section{Chapter Three}

\section{Research Design and Methodology}

Research Questions: Does CA provide a successful model of theoretically grounded framework of instruction for physical and occupational therapy patient education? Specifically the use of CA was hypothesized to: (1) improve ability to perform Activities of Daily Living (ADLs); (2) improve patient pain scores; (3) improve patient self-efficacy; (4) improve patient identified functional goals; (5) provide better patient knowledge outcomes; (6) provide greater patient understanding of their role in therapy; (7) provide patients with greater understanding of their condition; (8) improve patient satisfaction; (9) provide better patient compliance with home programs during and after therapy.

Hypothesis: It was anticipated that the results of this study would indicate that strong patient education using CA would result in improved patient outcomes and long-term compliance, changed patient attitudes, knowledge, and behaviors.

Dependent Variables: Outcome measurements were used to assess patient outcomes, including disability questionnaires, pain questionnaires, pre- and post-therapy knowledge of condition and activities/treatments to improve condition.

Independent Variable/s: Patient teaching using Cognitive Apprenticeship (CA) versus a traditional patient instruction/teaching.

Subjects: From January to June 2017, all patients who voluntarily consented to participate in the study seen at Rexburg Rehabilitation outpatient rehabilitation clinic were designated as the treatment group, while all patients who voluntarily consented to participation in the study seen at St. Anthony Rehabilitation outpatient rehabilitation clinic served as the control group. Patients were physician or self-referred and had a variety of diagnosis such as shoulder 
pain, back and neck problems, and knee problems that required patient education and the use of a home exercise program as part of their comprehensive plan of care. Patient participation was voluntary and informed consent was obtained.

Inclusion criteria: Patients who presented to the local outpatient therapy clinic either by self-referral or by physician referral for physical or occupational therapy evaluation and treatment.

Exclusion criteria: Patients that presented with known cognitive impairments by diagnosis or a diagnosis suggesting cognitive impairments were excluded from the study. Examples include, but are not limited to, Traumatic Brain injury or TBI, Advanced Parkinson's, Acute or subacute CVA/Stroke. Patients, who upon evaluation, were determined to have impairments that would inhibit their ability to participate in the research were also excluded (i.e. a patient with Parkinson's Disease, dementia, or autism). Other exclusions included patients who were seen clinically fewer than four times for total treatment and children under the age of 10 . Finally, patients were excluded who presented to the outpatient clinic but were not appropriate candidates for skilled physical or occupational therapy at this time, for example, a patient who presented for therapy but required referral to another provider through differential diagnosis.

Methods: All participants completed a variety of pre-test assessments that were applicable to their diagnosis: 6 Minute Walk Test (Appendix A), Upper Extremities: Activities of Daily Living Questionnaire (Appendix B), Lower Limb Questionnaire (Appendix C), Neck Disability Index (Appendix D), Pain Disability Questionnaire (Appendix E), Physical Activity Readiness or Par-Q Questionnaire (Appendix F), Activities of Daily Living Questionnaire (Appendix G), Oswestry Disability Questionnaire (Appendix H), Self-Efficacy for Exercise or SEE Scale (Appendix I), Patient Specific Functional Scale (Appendix J), and Patient Education - 
Assessment (Appendix K). Participants were assisted by a designated research assistant assigned to the clinic separate from the treating therapists in filling out pre- and post-test assessments.

At discharge, all participants completed the same assessments as post-tests. Patients were assessed for continued compliance with home exercise plans four-weeks post discharge.

Teaching Methods and Protocol: Physical Therapists in the Rexburg clinic were trained in CA by the principal investigator and used CA for patient education. The principal investigator had used CA for patient education for the past two years. Physical Therapists in the control group at the St. Anthony clinic did not receive training and continued using the traditional approach they have used in the past.

The CA trained Physical therapists followed the steps of CA: (1) Modelling. This included the therapists or expert demonstrating the exercise. It also included role playing a situation that may arise at home or work that would require a change in behavior. (2) Coaching. The patient practiced the skill while the therapist offers feedback and advice. (3) Scaffolding. As time went on, the therapist gave more and more responsibility to the patient while ensuring the exercise was being done properly. Patients were asked to demonstrate the exercise to the therapist or to another patient. (4) Articulation. The therapists asked the patient to explain how to do the exercise, or other important aspects of therapy why these were important, what activities were restricted and why. (5) Reflection. The therapists and patient compared the patient responses to what the therapist had taught them. (6) Exploration. The therapist suggested a new situation that may arise and asked the patient to determine what their behavior, choice of exercise, or intervention should be.

The control group followed typical education methods in that the therapist took a moment to explain to the patient their evaluative findings and provide some information regarding the 
patient's diagnosis, prognosis, and expected outcomes including a general timeframe. Therapists may give the patient a pictorial guide of the exercises they want the patient to perform and specify a quantity of sets to be performed. They may demonstrate to the patient what the exercise looks like and have the patient perform the exercise a time or two in the clinic before sending them home to work on these activities.

Ethical Considerations: IRB approval was obtained by the University of St. Augustine for Health Sciences human subjects committee that reviews research studies to ensure that patient considerations of safety, and ethical treatment are maintained at all times. Approval was also obtained by PMD Therapies, PLLC human subjects chair for this study. Patient confidentiality was maintained by ensuring that only the principal investigator and his assistants had access to patient records and identifying information. In accord with the Health Insurance Portability and Accountability act or HIPPA, all information was kept in a secure room and on a secure computer at all times. Potential conflicts of interests were addressed by ensuring patient rights to end participation in the study at any time and for any reason without repercussions. Also, patients were able to participate in study regardless of insurance carrier or payment status.

Statistical Methods and Analysis: This study was quantitative two-group design with non-random selection (i.e., self-referred patients to two outpatient clinical settings), and nonrandom assignment (i.e., patients coming into one clinic formed the control group and patients coming into another clinic the treatment group). The control clinic exposed patients to traditional patient instruction and treatment. The treatment clinic exposed patients to patient education that was grounded in Cognitive Apprenticeship (CA) model of instruction.

The research design was split plot with most of the analyses done as repeated measures ANCOVA (pre-test/post-test). There were parametric and non-parametric statistical tests used. 
Post measures were gathered on the last day of treatment and at four weeks after discharge. Both groups experienced the following measures both pre-treatment and post treatment:

\section{Standardized Pain Assessments}

* Knowledge Pretest/Knowledge Posttest

* Exercise Efficacy Scale

* Standardized Disability Assessment - specifically, the Patient-Specific Functional Scale.

* Activities of Daily Living Questionnaire

\section{* One of the following Additional Functional Measures}

* Lower Limb Questionnaire

* Oswestry Low Back Pain Scale

* Six-Minute Walk Test

* The Visual Analog Scale for Pain

* The Quick DASH

* The Low Back Pain Rating Scale

* Neck Disability Index

* Physical Activities Readiness Questionnaire (PAR-Q).

All descriptive and inferential statistics in this project were conducted using the Statistical Package for Social Sciences (SPSS ver. 24.0, 2016). The alpha level for rejecting the Null hypothesis was established at the .05 probability level and all statistics reported are onetailed unless otherwise specified.

There was a challenge associated with statistical analysis in this project in that the patients coming into the study had an assortment of physical and occupational therapy issues and did not take the same functional measures and disability indexes. All scores on all measures were 
normalized as Z-scores so patients could be compared across different clinical problem types. The statistical test on all repeated measures were repeated measures ANCOVA using the prescore as covariate.

What makes this study a split-plot design was that measures of patient satisfaction were measured post-study only as well as patient reporting of compliance. As such, the test of main effects between groups consisted of one between subject tests using one-way parametric statistics.

There were a number of face-sheet demographics that were collected at patient admission listed below:

* Age

* Gender

* Education - Highest Level Achieve

* Referral - self-referred -vs- patient-referred.

* Had Surgery (yes/no)

* Occupation

* Seen other specialists (therapy elsewhere (yes/no).

* Other medications taken.

Pre-measure group differences on these demographic variables were tested to determine that no selection threat was present. In addition, these variables were tested against the other analyses in this study to determine if they mediated or moderated the relationship as working covariates. All statistics were tested to make sure that they satisfied the assumptions associated with those statistics and adjustments in statistical approaches made if they failed their assumptions. 
Non-equivalency: There was no practical solution to the problem of non-equivalency of groups. Patients that experienced control conditions did not necessarily experience the same group of treating clinicians as those patients that experienced treatment conditions. Results from the data were analyzed for evidence of non-random error, but otherwise the problem of nonequivalency was not an insurmountable threat of internal validity.

Selection threat: Patients coming into the clinic offering the treatment condition had the possibility of having a higher level of education than the patients coming into the control condition because the Rexburg Rehabilitation clinic is located in a university town. As mentioned, the pre-data was analyzed for any selection threats and if one was present, appropriate mathematics (e.g., binomial probit models) were used to adjust values. Population age differential was statistically a selection threat but the age variable was not central to the results. Results of that analysis can be found in chapter four.

Testing Threat: It was possible that patients might retain some memory of the premeasure questions; however, this effect would affect both groups equally, which would show up as a random source of error versus non-random error.

Delimitations: The patients that participated lived in an area of the country that is more rural and with a higher proportion of Whites than in more urban areas. This fact limits the generalizability of the study results.

Summary: This study provided insight into the effectiveness of CA for patient education in outpatient physical therapy. By using an educational theoretically grounded model for patient education it was anticipated that patients in the treatment group would have higher outcome scores as it relates to patient improvement, patients would also show improvement post 
discharge with home exercise program compliance and have greater patient satisfaction with their therapy treatment. 


\section{Chapter Four}

The primary goal of this study was to examine the differences between patients who were provided patient education using Cognitive Apprenticeship (CA) during their therapy experience to patients who were provided patient education using traditional methods and no specific model for education. Use of CA was hypothesized to: (1) improve ability to perform Activities of Daily Living (ADLs); (2) improve patient pain scores; (3) improve patient self-efficacy; (4) improve patient identified functional goals; (5) provide better patient knowledge outcomes; (6) provide greater patient understanding of their role in therapy; (7) provide patients with greater understanding of their condition; (8) improve patient satisfaction; (9) provide better patient compliance with home programs during and after therapy.

The results of the study confirmed the hypothesis that patients using CA significantly improved the patient's ability to perform specific functional goals, knowledge outcomes, understand their role in therapy, understand their condition, and comply with home exercise programs. The results rejected the hypothesis that patients in the CA group improved function in ADLs, improve pain, have greater patient efficacy, and increased satisfaction.

Measures: Data collection for this study began in January of 2017 and finished in June of 2017. Participants in the treatment group were volunteer patients from the pool of patients who were either self-referred or physician referred to Rexburg Rehabilitation clinic in Rexburg, Idaho. Participants in the control group were volunteer patients who either self- referred or were physician referred to St. Anthony Rehabilitation clinic in St. Anthony Idaho. Both clinics are owned by the author. Patient selection was based primarily upon the clinic chosen by the patient for participation in physical/occupational therapy services. Patients who provided consent were 
included if they were seen for at least four patient visits, had no cognitive impairments or diagnosis that would preclude their ability to comprehend questionnaire information. Patients who were under the age of 10 were excluded from the study (see Table 4-A).

Table 4-A

Inclusions $\quad$ Exclusions

\begin{tabular}{ll}
\hline Patients who presented to the local outpatient & Patients with cognitive impairments \\
therapy clinic either by self-referral or by & Patients with other impairments that would \\
physician referral for physical or occupational & inhibit participation in the research \\
therapy evaluation and treatment. & Patients seen clinically fewer than 4 times \\
& Children under the age of 10 \\
& Patients not candidates for PT or OT
\end{tabular}

The study included 34 patients in the treatment group at Rexburg Rehabilitation that received CA patient education and 24 patients in the control group at St. Anthony Rehabilitation that received traditional patient education. Data was collected over a six-month period with a final participation rate of approximately $30 \%$ of those who were referred or came for therapy services at the two clinics. Seventy-four patients began the study and fifty-eight total patients completed the requirements, resulting in a $21 \%$ dropout rate. The participation in the study was lower than anticipated due to patients who withdrew from the study for relocation, rehospitalization, early discharge, or discontinuing therapy for lack of insurance coverage.

Statistical Process: The study outlined here is quantitative and consists of a number of between-subject comparisons and lesser number of within-subject comparisons of mean no s results. All descriptive and inferential statistics were analyzed using the Statistical Package for Social Sciences Version 24.0 (SPSS, 2016). The alpha level for rejecting the null hypothesis was established at the .05 probability level and all statistics reported are one-tailed unless otherwise 
specified. Levene's test for equality of variance was tested on all pairwise comparisons and will be reported if this statistical assumption has not been satisfied. There is a control group and a treatment group with pre-measures and post-measures. Table 4.0 describes the demographic variables that were recorded about the study sample and to assure that the two groups were similar enough that a comparison could be statistically evaluated. After demographic statistics are reported, a between subject (control versus treatment) was analyzed as an independent sample t-test, rather than ANOVA which derives the same value. Since the ultimate goal is to compare groups, while controlling for pre-scores, this first analysis will be used to make sure that a selection threat is not present; which would complicate the subsequent ANCOVA. There was descriptive data reported on the pre-test in this study that were later used to compare against post-tests of the same variable. An independent sample t- test was used to compare pre-measures in the control group against pre-measures in the treatment group Ideally, there would not be a difference between the pre-measures of the two groups statistically or we would have what is termed a selection threat; the two groups could not be said to have equivalent membership of some theoretical population of patients. In addition, later in this report it will be argued that ANCOVA is a more powerful way to conduct repeated measures with pre-measures acting a subject level control. The presence of a selection threat would make using ANCOVA problematic and we would have been forced to use a less powerful test. 
Participant Variables: Participant Characteristics examined is reported in table 4-0.

\begin{tabular}{|c|c|}
\hline \multicolumn{2}{|l|}{ Table 4-0 Participant Characteristics } \\
\hline Participant Characteristics Examined & Measurement Tool \\
\hline Patient Age & Patient Intake Data Form \\
\hline Patient Gender & Patient Intake Data Form \\
\hline Referral Source & Patient Intake Data Form \\
\hline Occupation & Patient Intake Data Form \\
\hline Surgery Occurred or Not & Patient Intake Data Form \\
\hline Educational Level & Patient Consent Form \\
\hline Activities of Daily Living (ADL) & Activities of Daily Living Questionnaire: Appendix B \\
\hline Outcome Measures per Diagnosis & $\begin{array}{l}\text { 6-Minute Walk Test: Appendix A } \\
\text { Lower Limb Questionnaire: Appendix C } \\
\text { Neck Disability Index: Appendix D } \\
\text { Par-Q: Appendix F } \\
\text { Oswestry Lower Back Pain Scale: Appendix H } \\
\text { Quick Dash: Appendix G }\end{array}$ \\
\hline Pain Disability & Pain Disability Questionnaire: Appendix E \\
\hline Self-Efficacy for Exercise & Self-Efficacy for Exercise: Appendix I \\
\hline Patient Function & Patient Specific Function Scale: Appendix J \\
\hline Patient Education Assessment & Appendix K \\
\hline Patient Satisfaction with Care & Phone Survey \\
\hline Home Exercise Compliance & Phone Survey \\
\hline
\end{tabular}

\section{Descriptive Statistics of Study Population:}

In Table 4-1 the reported total of participants does not equal the number of participants in the study due to patients not reporting their age. As the reader can discern, the mean age of participants who were part of the control group were older than participants in the treatment group. 
Table 4-1. Descriptive Statistics for Age by Group Assignment

\begin{tabular}{cccc} 
Variable & $n$ & $M$ & $S D$ \\
\hline Control & 24 & 65.00 & 8.856 \\
Treatment & 28 & 44.25 & 19.843 \\
\hline
\end{tabular}

The standard deviations diverge significantly. In a one sample t-test of the differences between the means, the analysis failed the Levene's test so Levene's degrees of freedom and critical values are reported here, and, as the reader can discern, the difference between these means is statistically significant, $t(38.56)=4.73 p=.00$. The average age was significantly different. The treatment group had a larger standard deviation, meaning there was a larger age variation in the treatment group compared to the control group. This is because the demographics of the cities in which the clinics are located are quite different. The treatment clinic is in a college town with a large, young population. The control group is in an aging rural community. Therefore, the samples are different even though they reflect the population from which they were drawn. While this could be an indication of a selection threat caused by an unequal number of test subjects having similar subject related variables that threaten the validity of the study, age in not considered to be a significant variable in this study.

Table 4-2. Crosstabs of Gender by Group Assignment

\begin{tabular}{crrr}
\hline & \multicolumn{3}{c}{ Gender } \\
& Male & Female & Total \\
\hline Control & 14 & 10 & 24 \\
Treatment & 21 & 13 & 34 \\
Total & 35 & 23 & 58 \\
\hline
\end{tabular}


Gender by group assignment crosstabs are reported in table 4-2. In a Chi Square test of independence, observed values for the distribution of males and females was not statistically anomalous, $\chi^{2}(0.69) p=.39$

Data was collected to determine if participants' have or have not experienced surgery previously. A crosstab of this variable by group assignment is reported in table 4-3.

Table 4-3. Crosstabs of Surgery by Group Assignment

\begin{tabular}{cccr}
\hline & \multicolumn{3}{c}{ Surgery } \\
& $\mathrm{N}$ & $\mathrm{Y}$ & Total \\
\hline Control & 11 & 13 & 24 \\
Treatment & 15 & 19 & 34 \\
Total & 26 & 32 & 58 \\
\hline
\end{tabular}

In a Chi Square test of independence, observed values for the distribution of "had or did not have surgery" by group selection was not statistically anomalous, $\chi^{2}(0.17) p=.45$

Descriptive statistics for Activities of Daily Living are reported in table 4-4. It is here, and with subsequent variables of its kind that a selection threat would be unwelcomed. The assessment tool for this variable was the Activities of Daily Living Questionnaire: Appendix B. This questionnaire assesses the patient's perceptions of limitations in areas of function at evaluation and again at discharge If there were significant differences between the groups, then these populations were not homogeneous and could not able to be compared to each other. 
Table 4-4. Descriptive Statistics of Activities of Daily Living by Group Assignment

\begin{tabular}{cccc} 
Variable & $n$ & $M$ & $S D$ \\
\hline & & & \\
Control & 24 & 3.46 & 1.50 \\
Treatment & 28 & 3.67 & 1.96 \\
\hline
\end{tabular}

An independent sample t-test revealed that the mean differences in comparing the control group with the treatment group on Activities of Daily Living was not statistically significant, $t(55)=-.435, p=.67$. Therefore, we can assume that no selection threat was present concerning level of independence and can proceed in an unambiguous way on pre/post comparisons of this variable. A bar graph of this relationship can be viewed in figure 4-1. Whisker lines represent the $95 \%$ confidence interval.

Figure 4-1. Bar Chart of ADL by Group

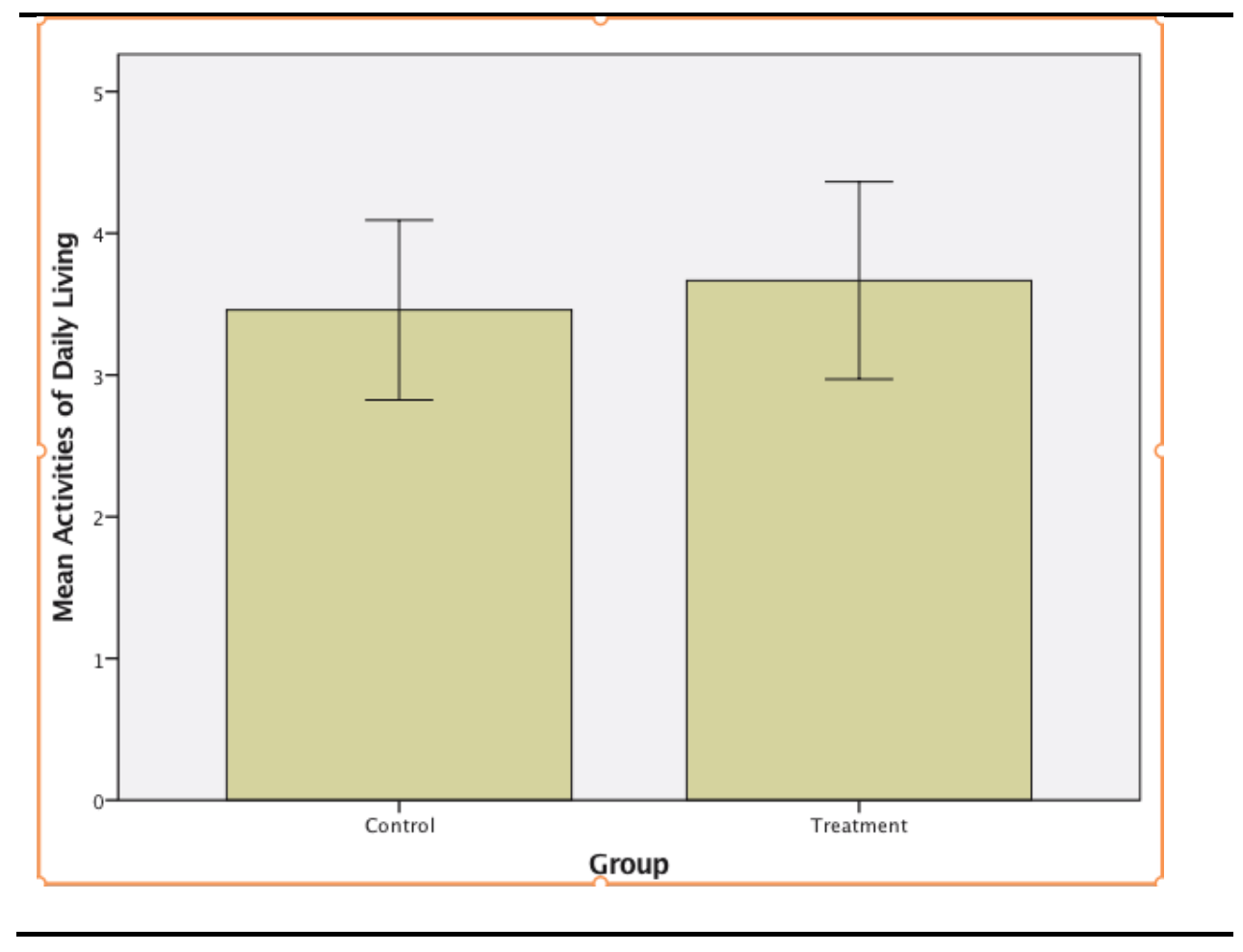


Descriptive statistics for measures coming from the Pain Disability Questionnaire Activities are reported in table 4-5.

Table 4-5. Descriptive Statistics for Pain Disability by Group Assignment

\begin{tabular}{cccc} 
Variable & $n$ & $M$ & $S D$ \\
\hline Control & 23 & 58.91 & 27.74 \\
Treatment & 34 & 59.35 & 34.16 \\
\hline
\end{tabular}

An independent sample t-test revealed that the mean differences in comparing the control group with the treatment group on measures of Pain Disability were not statistically significant, $t(55)=-.051, p=.48$. Therefore, we can assume that no selection threat was present concerning pain and can proceed in an unambiguous way on pre/post comparisons of this variable. A bar graph of this relationship can be viewed in figure 4-2.

Figure 4-2. Bar Chart of Pain Disability by Group

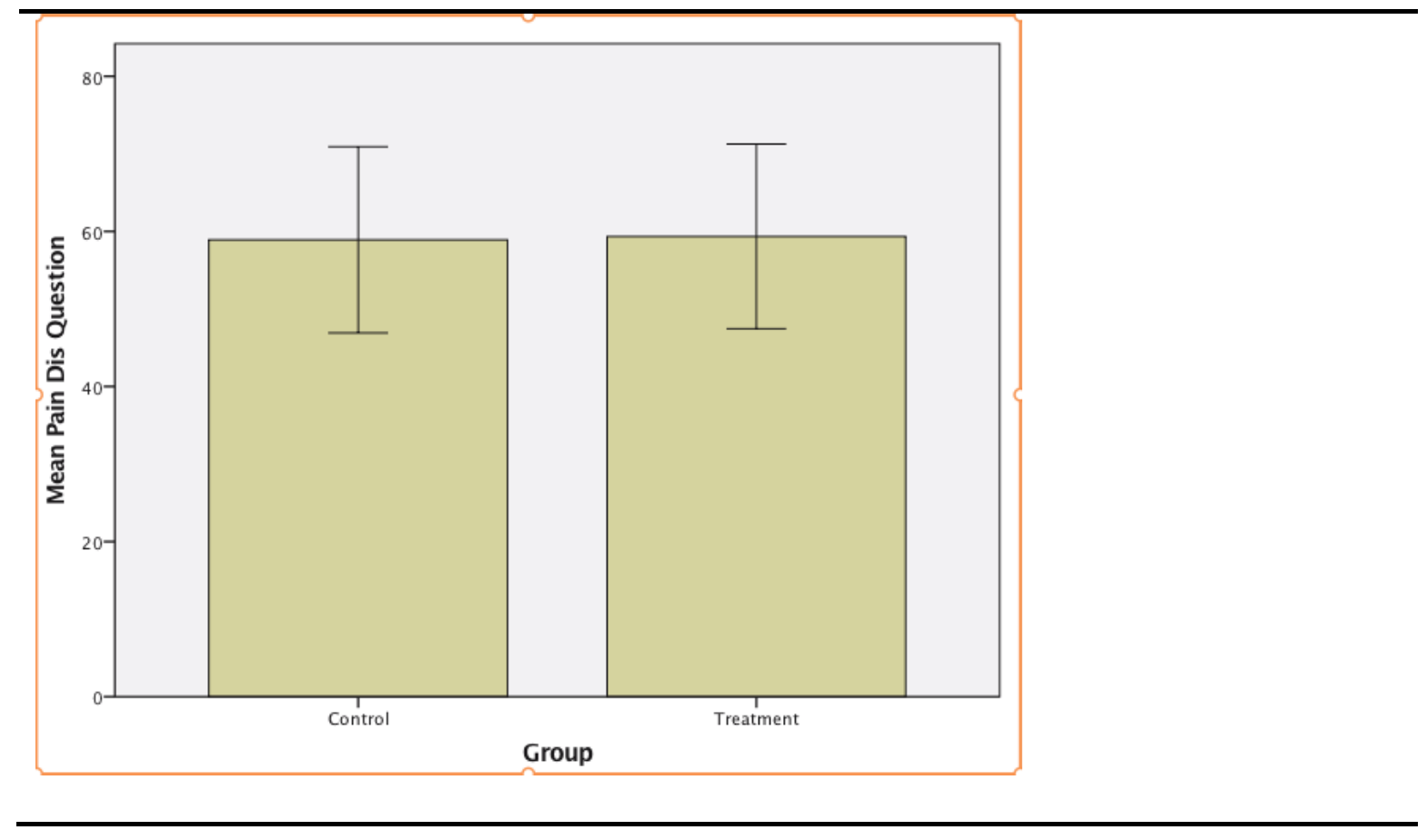


Descriptive statistics for measures coming from the Self Efficacy for Exercise Scale are reported in table 4-6. This variable is important because a significant difference would prove the hypothesis that the use of CA for patient education effects self-efficacy.

Table 4-6. Descriptive Statistics for Self-Efficacy for Exercise by Group Assignment

\begin{tabular}{cccc} 
Variable & $n$ & $M$ & $S D$ \\
\hline Control & 24 & 50.79 & 21.86 \\
Treatment & 34 & 54.15 & 23.43 \\
\hline
\end{tabular}

An independent sample t-test revealed that the mean differences in comparing the control group with the treatment group on Self-Efficacy for Exercise was not statistically significant, $t(56)=-.552, p=.29$. Therefore, we can assume that no selection threat was present due to selfefficacy and can proceed in an unambiguous way to pre/post comparisons of this variable. A bar graph of this relationship can be view in figure 4-3. This data rejects the hypothesis. that selfefficacy would improve by the use of CA for patient education.

Figure 4-3. Bar Chart of Self-Efficacy for Exercise by Group

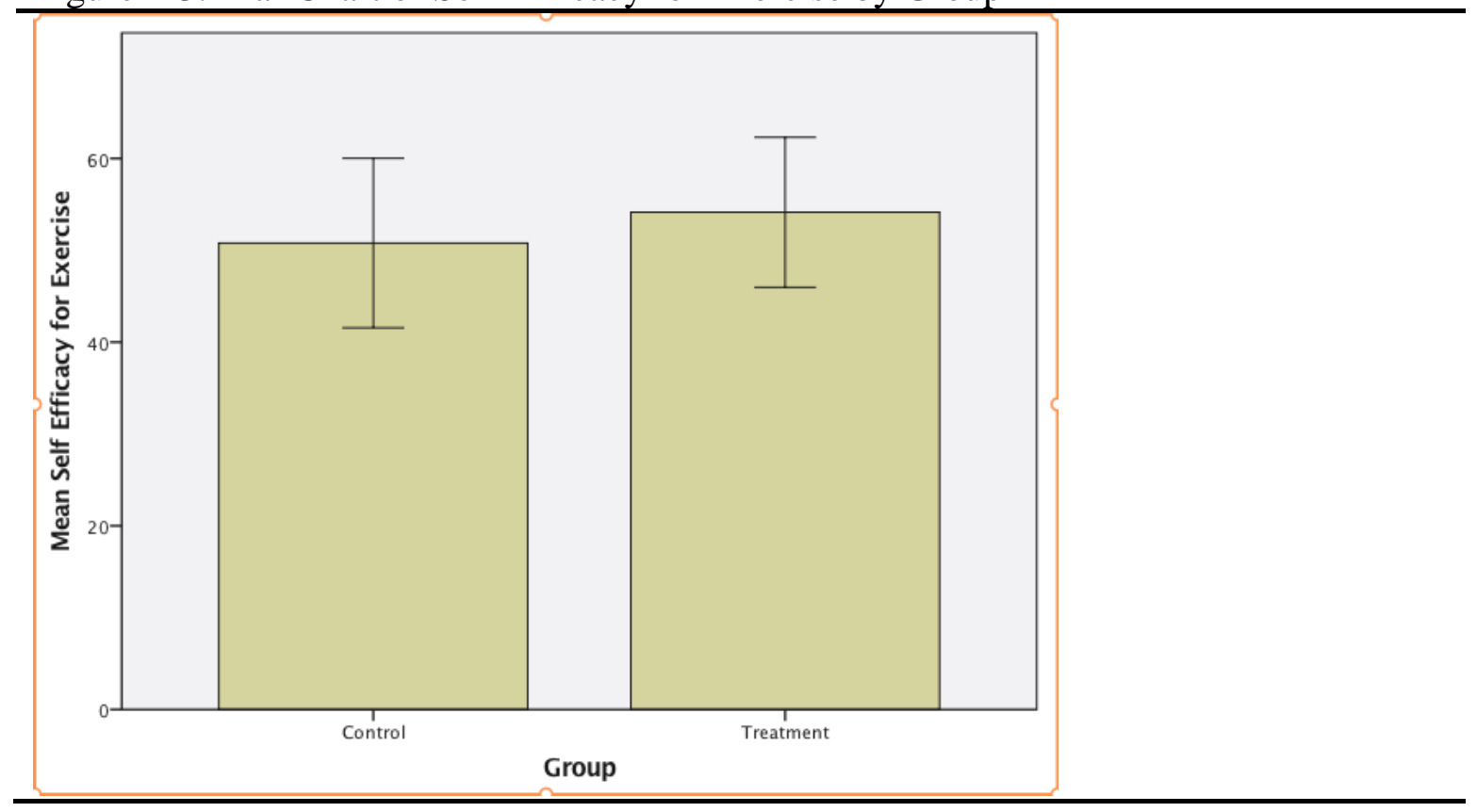


Descriptive measures coming from the Patient Specific Functional Scale by group reported in table 4-7. This measurement tool was selected because it lists 3 specific activities that are identified by patients as important to them that they are unable in contrast to the ADL questionnaire, which identifies patient's level of function in general activities of daily living.

Table 4-7. Descriptive Statistics for Patient Specific Functional Scale by Group Assignment

\begin{tabular}{cccc} 
Variable & $n$ & $M$ & $S D$ \\
\hline & & & \\
Control & 24 & 10.75 & 8.05 \\
Treatment & 34 & 11.15 & 5.79 \\
\hline
\end{tabular}

Independent sample t-test revealed that the mean differences in comparing the control group with the treatment group on Patient Specific Functional Scale was not statistically significant, $t(56)=-.219, p=.41$. Therefore, we can assume that no selection threat due to difference in functional levels between the groups was present and can proceed in an unambiguous way to pre/post comparisons of this variable. A bar graph of this relationship can be viewed in figure 4-4.

Figure 4-4. Bar Chart of Patient Specific Function by Group

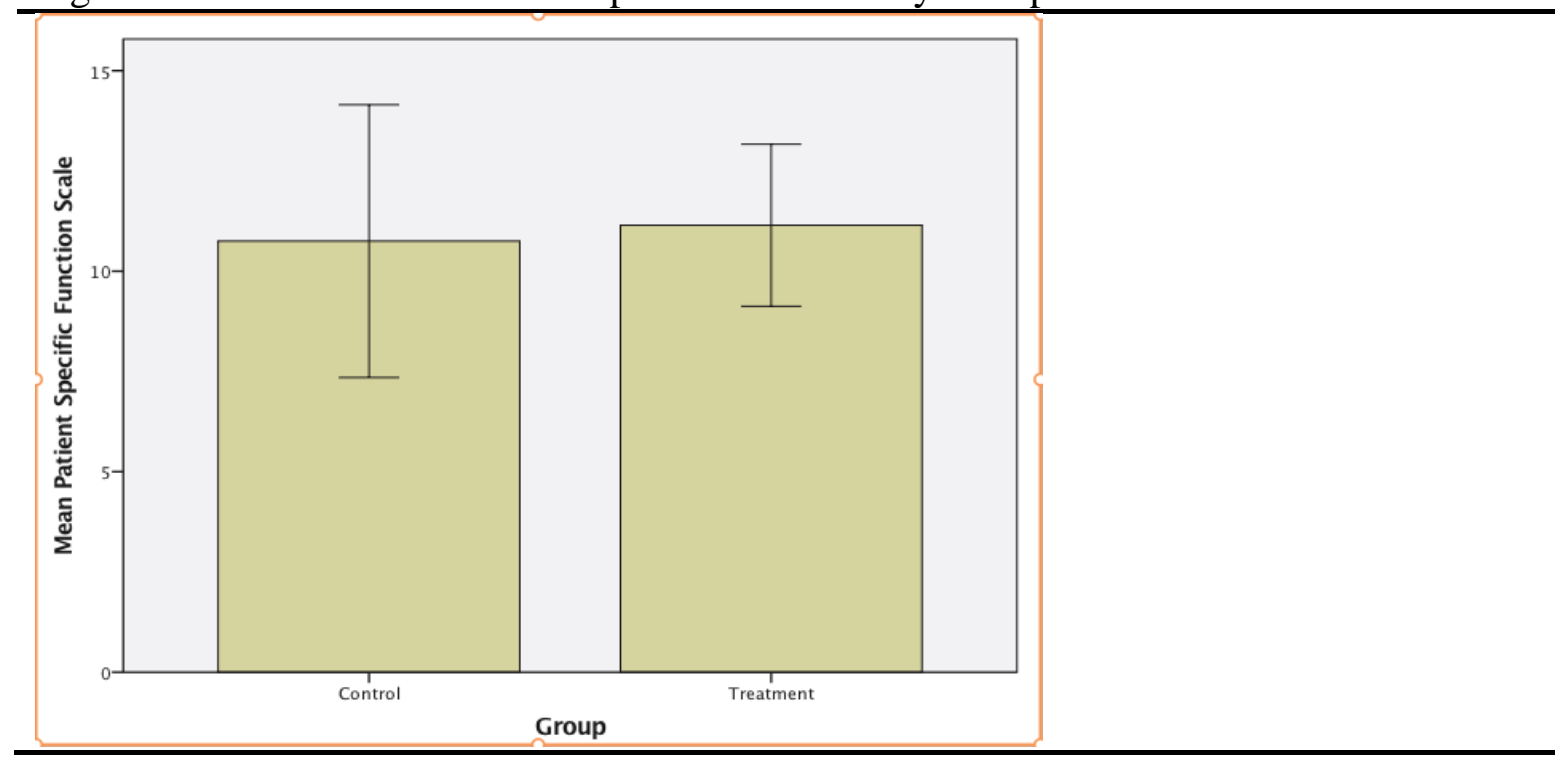


Descriptive statistics for pre-knowledge of patient condition, patient role, general guidelines for participation in therapy, and patient understanding of what to do better manage their health is reported in table 4-8. This was measured by a pre-test of twenty questions that assessed patient knowledge before patient education on pain, swelling, inflammation, exercise, patient responsibility, and provider responsibility. See Appendix K.

Table 4-8. Descriptive Statistics for pre-knowledge measure by Group Assignment

\begin{tabular}{cccc} 
Variable & $n$ & $M$ & $S D$ \\
\hline Control & 24 & 11.10 & 2.86 \\
Treatment & 34 & 12.16 & 2.21 \\
\hline
\end{tabular}

Independent sample t-test revealed that the mean differences in comparing the control group with the treatment group on a Pretest of knowledge about their health and the healthcare system were not statistically significant, $t(56)=-1.59, p=.06$. Therefore, we can assume that no selection threat was present due to differences in the control and treatment group's preknowledge and can proceed in an unambiguous way on pre/post comparisons of this variable. A bar graph of this relationship can be view in figure 4-5.

Figure 4-5. Bar Chart of Pre-knowledge measure by Group

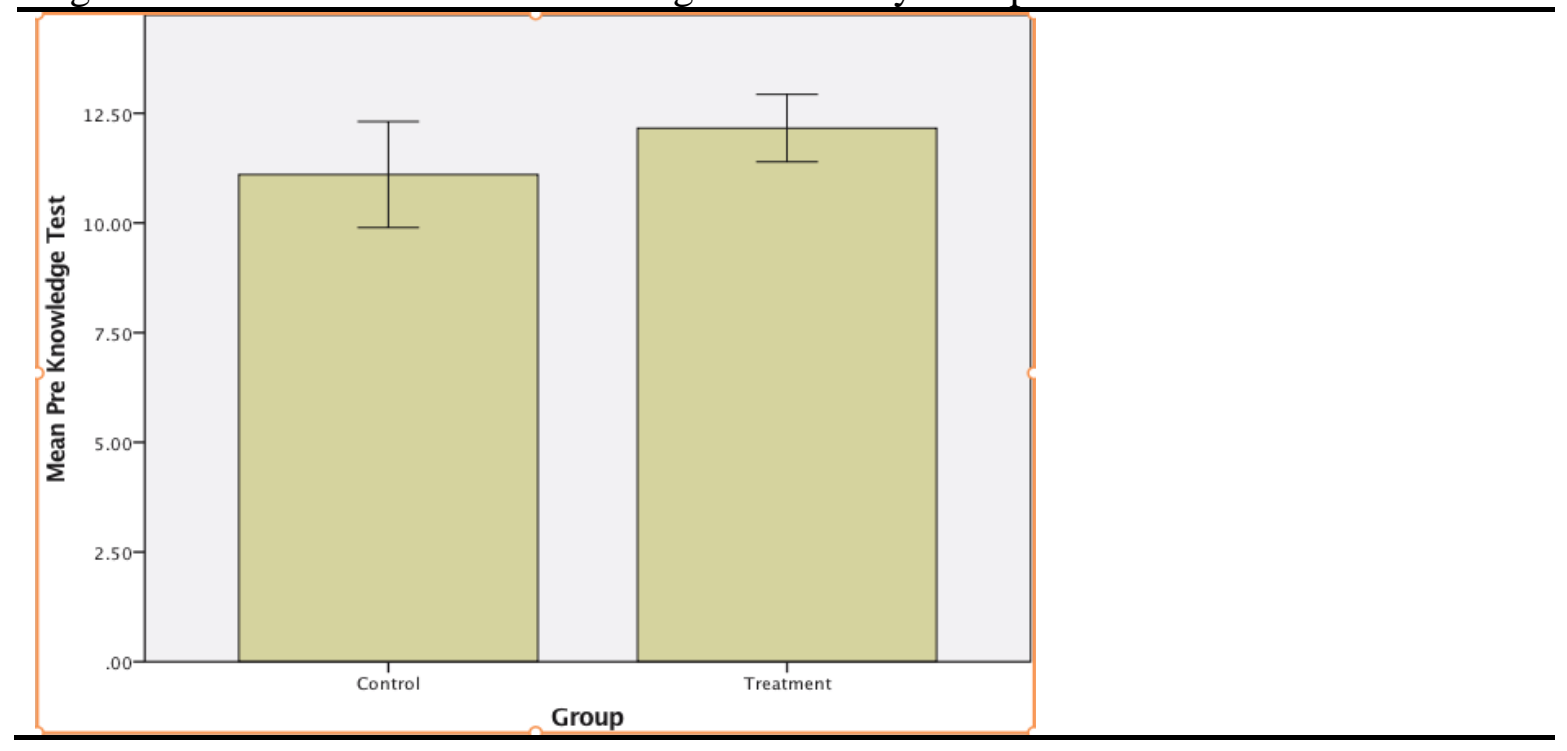




\section{Within-Subject Variability}

The principle analysis of this study is to determine if the treatment group produced superior outcomes in comparison with the control group while controlling for those same premeasures. In measuring pre-post differences there are different ways to think about what type of analysis is most appropriate. If the research question seeks to inquire if the mean change in outcome differed in two groups, then a classic split plot design with treatment group as the between subject factor, time as a within factor, and using the time*group interaction term to test the hypothesis is appropriate. However, if the question is whether post-test means, adjusted for pre-test scores, differ between groups, then ANCOVA is recommended. This issue has a long history and is best known as the Lord's Paradox, taken from the classic psychometric work of Lord (1967). More contemporary treatment of this issue is addressed in the works of Catell (1983), McFarland and Ryan (2006), Singer \& Willett (2003), and McArdle (2009). This study is interested in post-test means adjusted for pre-measures so the following analysis were conducted as ANCOVA, with post measures serving as the dependent measure, group as a fixed effect, and pre-measures serving as a covariate. The use of ANCOVA for statistical analysis was chosen as it is the most powerful way to perform post measure analysis using individual premeasures for each measure as controls.

\section{Hypothesis 1: Patients educated with CA will improve their ability to perform} Activities of Daily Living (ADLs). It was anticipated that the use of CA in teaching patients would positively affect their ADL scores through the increased knowledge acquired and increased level of patient empowerment. As patients learned more about their condition and how to manage it, they would improve their ADL scores better than those who had not received 
specific instruction using CA. Descriptive and inferential statistics for pre-post comparisons for the variable Activities of Daily Living are reported in tables 4-9 and 4-10.

Table 4-9. Means and Standard Deviations for Activities of Daily Living by groups

\begin{tabular}{l|lll}
\hline Variable & $n$ & $M$ & $S D$ \\
\hline Control & & & \\
Pre ADA & 24 & 3.46 & 1.503 \\
Post ADA & 24 & 2.50 & 2.322 \\
& & & \\
\hline Treatment & & & \\
Pre ADA & 33 & 3.46 & 1.503 \\
Post ADA & 33 & 3.67 & 1.963 \\
\hline
\end{tabular}

The reader can discern from the summary ANCOVA table 4-10, that when Activities for Daily Living post-means are adjusted for their concomitant pre-test scores, a between subjects group effect was found to be statistically non-significant, $F(1,57)=.008, p=.23$ and a very small eta squared value, $\eta_{p}^{2}=0.051$. The results rejected the hypothesis that the CA group would be significantly more independent in ADL's than the control group. Thus, the use of CA did not provide the anticipated outcome of increased patient scores on the ADL outcomes assessment. In other words, there was not a significant difference in their reports of ability to accomplish the basic tasks of daily living.

Table 4-10. Summary ANCOVA table for Post-Activities for Daily Living adjusted for its premeasure

\begin{tabular}{lclllll}
\hline Model & $S S$ & $d f$ & $M S$ & $F$ & $p$. & $\eta_{p}{ }^{2}$ \\
\hline Corrected Model & 93.335 & 2 & 47.667 & 12.82 & .000 & \\
Intercept & .057 & 1 & .057 & & & \\
PreADL & 95.18 & 1 & 26.61 & & .23 & .051 \\
Group & 0.31 & 1 & 0.31 & .008 & & \\
Error & 200.700 & 54 & 3.17 & & & \\
Total & 670.00 & 57 & & & & \\
Corrected Total & 296.035 & 56 & & & & \\
\hline
\end{tabular}


Hypothesis 2: Patients educated with CA will have improved patient pain scores. It was anticipated that the use of CA in helping patients understand pain and its role in injury and healing would give patients greater understanding about pain and help them to lower their pain by understanding their condition better. Descriptive and inferential statistics for pre-post comparisons for the Pain Disability measure are reported in tables 4-11 and 4-12.

Table 4-11. Means and Standard Deviations for measure of Pain Disability Questionnaire by groups

\begin{tabular}{l|lll}
\hline Variable & $n$ & $M$ & $S D$ \\
\hline Control & & & \\
Pre PDQ & 24 & 58.91 & 27.74 \\
Post PDQ & 24 & 36.33 & 26.49 \\
& & & \\
Treatment & & & \\
Pre PDQ & 34 & 59.35 & 34.16 \\
Post PDQ & 34 & 31.56 & 34.67 \\
\hline
\end{tabular}

The reader can discern from the summary ANCOVA table 4-12, that when Pain Disability post-means are adjusted for their concomitant pre-test scores, a between subjects group effect was found to be statistically non-significant, $F(1,57)=.003, p=.13$ and a very small eta squared value, $\eta_{p}^{2}=0.006$. The results rejected the hypothesis that the CA group would be significantly different in their pain rating. Unfortunately post analysis showed that the use of CA did not provide sufficient differences in pain rating when compared with the control group. As can be seen in Table 4-11, this does not mean that patients in the CA group did not experience a decrease in pain - the decrease is very meaningful. However, CA group's mean change did not differ significantly from the control group who also experienced a meaningful decrease in pain. 
Table 4-12. Summary ANCOVA table for Pain Disability Questionnaire measure adjusted for its premeasure

\begin{tabular}{|c|c|c|c|c|c|c|}
\hline Model & $S S$ & $d f$ & $M S$ & $F$ & $p$. & $\eta_{p}{ }^{2}$ \\
\hline Corrected Model & 24987.98 & 2 & 12493.99 & 22.60 & .000 & \\
\hline Intercept & 494.96 & 1 & 494.96 & & & \\
\hline PrePDQ & 24833.63 & 1 & 44.92 & & & \\
\hline Group & 182.632 & 1 & 182.632 & .003 & .13 & .006 \\
\hline Error & 200.700 & 54 & 3.17 & & & \\
\hline Total & 670.00 & 57 & & & & \\
\hline Corrected Total & 296.035 & 56 & & & & \\
\hline
\end{tabular}

\section{Hypothesis 3: Patients educated with CA will have improved patient self-efficacy.}

The use of CA was anticipated to improve patient self-efficacy while performing exercise during and after therapy. Self-efficacy is described as an individual's confidence in their ability to get to an intended or anticipated outcome or result. When patient education using the CA, model was used self-efficacy would be an area anticipated to improve. Since individuals who have greater understanding about their health and healthcare should have greater confidence in their ability to improve their condition. Descriptive and inferential statistics for pre-post comparisons for the variable Self-Efficacy are reported in tables 4-13 and 4-14.

Table 4-13. Means and Standard Deviations for Self-Efficacy for Exercise by groups

\begin{tabular}{llll}
\hline Variable & $n$ & $M$ & $S D$ \\
\hline Control & & & \\
Pre SEE & 24 & 50.79 & 21.86 \\
Post SEE & 24 & 54.15 & 23.43 \\
& & & \\
\hline Treatment & & & \\
Pre SEE & 33 & 59.35 & 34.16 \\
Post SEE & 33 & 61.24 & 22.80 \\
\hline
\end{tabular}


As can be seen in the ANCOVA results show in Table 4-14, when Self-Efficacy for Exercise post-means are adjusted for their concomitant pre-test scores, a between subjects group effect was found to be statistically non-significant, $F(1,58)=.274, p=.075$ and a very small eta squared value, $\eta_{p}^{2}=0.005$. The results rejected the hypothesis that the CA group would be significantly higher self-efficacy than the control group. This result was not anticipated and might be explained by the selection of the outcome measure used, as it pertained solely to the use of exercise to measure patient self-efficacy.

Table 4-14. Summary ANCOVA table for Self-Efficacy for Exercise measure adjusted for its premeasure

\begin{tabular}{lllrlll} 
Model & $S S$ & $d f$ & \multicolumn{1}{l}{$M S$} & \multicolumn{1}{l}{. } & \multicolumn{1}{c}{$\eta_{p}{ }^{2}$} \\
\hline Corrected Model & 14238.13 & 2 & 7119.07 & 25.67 & .000 & \\
Intercept & 4547.61 & 1 & 4547.61 & & & \\
PreSEE & 13933.67 & 1 & 50.25 & & .15 & .005 \\
Group & 75.99 & 1 & 75.99 & .274 & & \\
Error & 200.700 & 54 & 3.17 & & & \\
Total & 670.00 & 57 & & & & \\
Corrected Total & 296.035 & 56 & & & & \\
\hline
\end{tabular}

\section{Hypothesis 4: Patients educated with CA will have improved patient identified}

functional goals. Descriptive and inferential statistics for pre-post comparisons for the variable Patient Specific Functional Scales are reported in tables 4-15and 4-16.

Table 4-15. Means and Standard Deviations for Activities for Patient Specific Function by groups.

\begin{tabular}{llll}
\hline Variable & $\mathrm{n}$ & $\mathrm{M}$ & $\mathrm{SD}$ \\
\hline Control & & & \\
Pre PSF & 24 & 10.75 & 8.05 \\
Post PSF & 24 & 17.50 & 7.05 \\
& & & \\
\hline & & & \\
Treatment & & & 5.80 \\
Pre PSF & 34 & 11.15 & 8.33 \\
Post PSF & 34 & 21.24 & \\
\hline
\end{tabular}


The reader can discern from the summary ANCOVA table 4-16, when Patient Specific Function post-means are adjusted for their concomitant pre-test scores, a between subjects group effect was found to be statistically significant, $F(1,58)=3.09, p=.042$, but with small eta squared value, $\eta_{p}^{2}=0.053$. The results support the hypothesis that the CA group would be significantly better at performance of patient identified functional activities than the control group. In other words, the patients treated using CA performed significantly better on the specified functional activities related to their presenting condition.

Table 4-16. Summary ANCOVA table for Patient Specific Function Scale adjusted for its premeasure

\begin{tabular}{lclllll} 
Model & $S S$ & $d f$ & $M S$ & $F$ & $p$. & $\eta_{p}{ }^{2}$ \\
\hline Corrected Model & 249.496 & 2 & 124.75 & 2.029 & .141 & \\
Intercept & 4959.37 & 1 & 4959.37 & & & \\
PrePSF & 53.199 & 1 & 53.199 & & .042 & .053 \\
Group & 190.21 & 1 & 190.21 & 3.09 & & \\
Error & 200.700 & 54 & 3.17 & & & \\
Total & 670.00 & 57 & & & & \\
Corrected Total & 296.035 & 56 & & & & \\
\hline
\end{tabular}

\section{Hypothesis 5, 6 and 7: Patients educated with CA will have improved patient} knowledge outcomes, greater understanding of their role in therapy, and greater understanding of their condition. Descriptive and inferential statistics for pre-post comparisons for the variable knowledge are reported in tables 4-17 and 4-18.

Table 4-17. Means and Standard Deviations for Knowledge by groups.

\begin{tabular}{l|llc}
\hline Variable & $\mathrm{n}$ & $\mathrm{M}$ & $\mathrm{SD}$ \\
\hline Control & & & \\
Pre Know & 24 & 11.04 & 2.86 \\
Post Know & 24 & 12.16 & 2.21 \\
& & & \\
& & & \\
Treatment & & & \\
Pre Know & 34 & 11.15 & 5.80 \\
Post Know & 34 & 14.57 & 2.15 \\
\hline
\end{tabular}


The reader can discern from the summary ANCOVA table 4-18, when Measures of Knowledge post-means are adjusted for their concomitant pre-test scores, a between subjects group effect was found to be statistically significant, $F(1,57)=22.48, p=.000$ and a modest eta squared value, $\eta_{p}{ }^{2}=0.053$. The results support the hypothesis that the CA group would be significantly more knowledgeable about their health and the healthcare system than the control group.

Table 4-18. Summary ANOVA table for Knowledge adjusted for its premeasure

\begin{tabular}{lllrlll}
\hline Model & \multicolumn{1}{l}{$S S$} & $d f$ & \multicolumn{1}{c}{$M S$} & \multicolumn{1}{l}{. } & \multicolumn{1}{c}{$\eta_{p}{ }^{2}$} \\
\hline Corrected Model & 223.56 & 2 & 111.77 & 23.78 & .00 & \\
Intercept & 144.48 & 1 & 144.48 & & & \\
PreKnow & 72.02 & 1 & 72.02 & & & \\
Group & 105.67 & 1 & 105.67 & 22.48 & .000 & .29 \\
Error & 200.70 & 54 & 3.17 & & & \\
Total & 670.00 & 57 & & & & \\
Corrected Total & 296.035 & 56 & & & & \\
\hline
\end{tabular}

Although of tertiary interest, it is worth investigating if there was a relationship between age and knowledge gained. To investigate this variable, a change score was created (i.e., Post Knowledge - Pre-Knowledge) and then a Pearson Correlation was performed. As the reader can discern from Table 4-19, there is a small, but statistically significant relationship between age and knowledge gained. Younger patients, on average, showed a small advantage over older patients in acquisition of knowledge. To determine if age mediated the statistically meaningful relationship between the control and intervention group on post-score knowledge differences adjusted for individual pre-knowledge scores, age was added as a covariate. Subsequently, the F value for the group attenuated, $\mathrm{F}(1,48),=11.902, \mathrm{p}=001$. As the reader may discern, it reduced the F value for group approximately in half, however, it remained statistically significant. 
Table 4-19. Correlation Between Age and Pre-Operative Knowledge Gain Scores

\begin{tabular}{llrr}
\hline & & Age & Knowledge Gain \\
\hline Age & Pearson & 1 & -.249 \\
& Correlation & & \\
& Sig. (1-tailed) & & .038 \\
$\mathrm{~N}$ & 52 & 52 \\
\hline
\end{tabular}

\section{Hypothesis 8: Patients educated with CA will have improved patient satisfaction.}

Descriptive and inferential statistics for pre-post comparisons for the variable patient satisfaction rating are reported in table 4-20. Patient satisfaction was rated high for both the control group and the treatment group. In the treatment group, 30 of the 34 patients or $88 \%$ of the patients in the treatment group were highly satisfied and ranked their experience 8 or higher on a 1-10 scale. One person ranked their satisfaction less than 4 . In the control group, 18 of 24 or $75 \%$ of the patients ranked their experience 8 or higher. Two patients ranked their satisfaction less than 4 . The results while convincing at first view are not statistically significant when compared using ANOVA. The high satisfaction ratings are likely due to the ceiling effect often experienced in clinical data where the patient may just like the therapist. The results reject the hypothesis that patients educated with CA have improved patient satisfaction as compared to the control group.

Table 4-20 Patient Satisfaction Rating

\begin{tabular}{lccccc}
\hline Group & $n$ & $1 / 10$ to $4 / 10$ & $5 / 10$ to $8 / 10$ & $8 / 10$ or higher & percentage \\
\hline Treatment & 34 & 1 & 3 & 30 & $88 \%$ \\
Control & 24 & 2 & 4 & 18 & $75 \%$ \\
\hline
\end{tabular}


Table 4-21 Summary ANCOVA table for Patient Satisfaction Rating

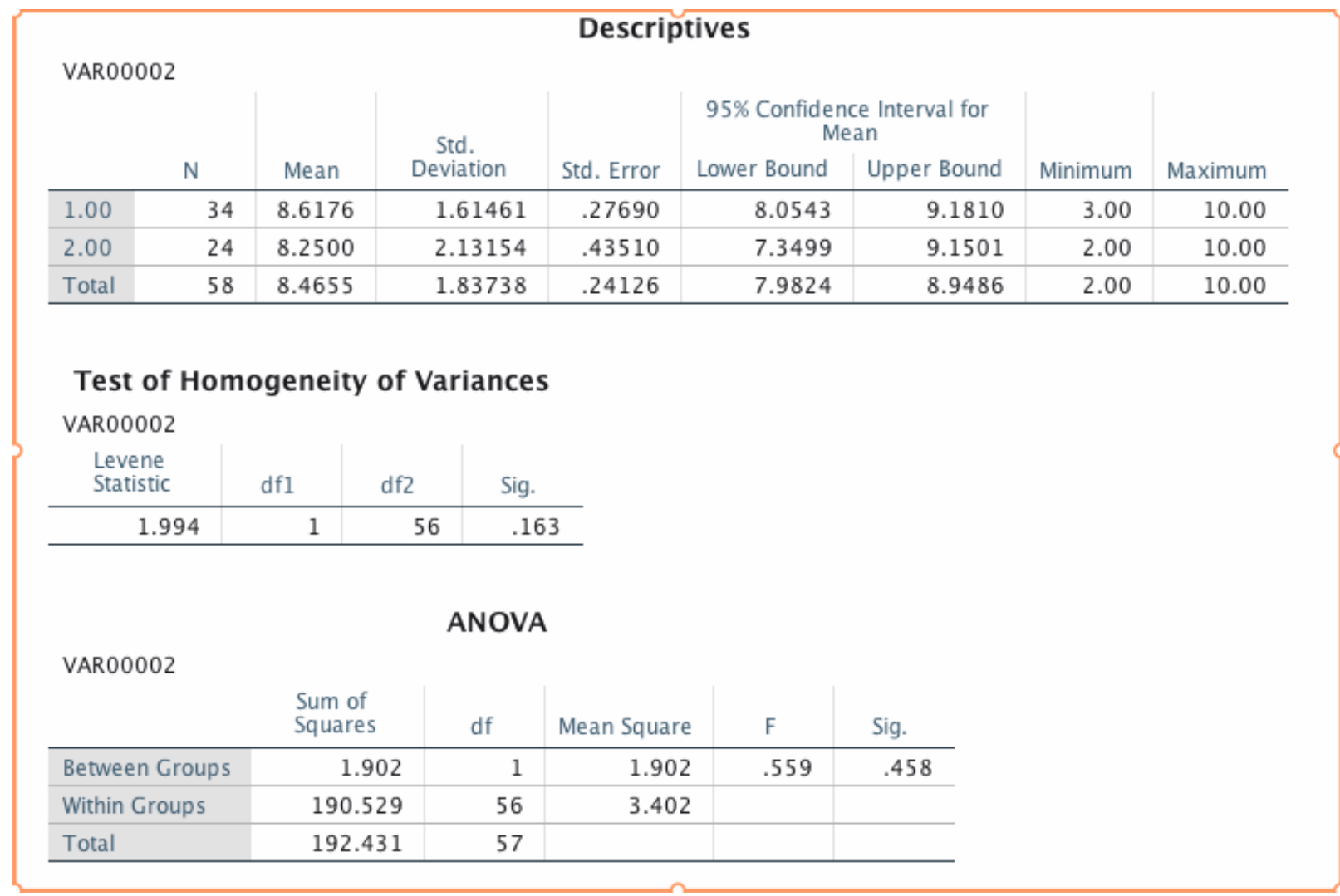

\section{Hypothesis 9: Patients educated with $\mathrm{CA}$ will have better patient compliance with}

home programs during and after therapy: A phone call follow up interview at 4-weeks postdischarge provided the following information: From the 34 patients in the treatment group, 25 were still performing their daily home exercises as prescribed at four-weeks post-discharge. This means that $74 \%$ of the patients continued to perform the prescribed home exercises. In the control group of the 24 patients, 8 were still performing the home exercises as prescribed or $33 \%$ of the sample. The statistics for a Chi-Square test for variable Home Exercise Compliance are reported in table 4-22. The results support the hypothesis that patients educated with CA have significantly better compliance with home exercise programs. 
Table 4-22. Crosstabs of Patient Compliance with Continued Exercise

\begin{tabular}{ccccc}
\hline & & & & \\
& & \multicolumn{2}{c}{ Type of Instruction } & \\
& & Treatment & Control & Total \\
\hline \multirow{2}{*}{ Still Doing Exercise } & Count & 25 & & \\
& Expected Count & 19.3 & 13.7 & 33 \\
Not Doing Exercise & Count & 9 & 16 & 33 \\
& Expected Count & 14.7 & 10.3 & 25 \\
Total & & 34 & 24 & 58 \\
\hline
\end{tabular}




\section{Chapter Five}

Summary/Conclusion: The primary goal of this study was to examine the relationship between patients who were provided patient education using CA during their therapy experience and patients who were provided patient education using traditional methods and no specific model for education. It is clear that the use of CA provided better knowledge outcomes. Patients educated CA had better patient outcomes and better patient compliance with home programs.

There are three areas where the patients who were treated using CA method were significantly different than the control group. 1) Patient Specific Function Activities Analysis increased significantly from 11.15 to 21.24 versus 10.75 to 17.50 . 2) Knowledge about their condition and how to manage it increased significantly from 11.15 to 14.57 questions answered correctly in the treatment group compared to 11.04 to 12.16 in the control group. 3) Patients who were continuing their exercises 4 weeks post-discharge was $74 \%$ versus $33 \%$ in the control group.

After data was collected and analyzed the findings support the primary hypothesis: patient education using CA will result in improved patient outcomes and long-term compliance, changed patient attitudes, knowledge, and behaviors, specifically: (1) improve patient identified functional goals; (2) provide better patient knowledge outcomes; (3) provide greater patient understanding of their role in therapy; (4) provide patients with greater understanding of their condition; (5) provide better patient compliance with home programs during and after therapy.

Patients who were treated with CA as an instructional model did statistically better than the control group when looking at their patient specific function scales or the functional goals they selected for themselves. This can be explained by the therapist spending more time with the patient teaching them using CA and focusing on the patient's main goals when that attended therapy. Additionally, when patients are more involved in their care their communication about their desired goals regarding their function, the use of CA was able to make a difference in their 
outcome scores. Patients improved in areas that were specifically important to them. This may be an indication that individual motivation does indeed play a factor in outcomes of ADL performance in individuals receiving therapy. This also would suggest that when patients have specific tasks or abilities that they identify with their therapist as goals, patient education can be used to help patients achieve those task specific goals in therapy. Individuals who received CA patient education demonstrated significant improvement in knowledge about their condition, the importance of therapy and the importance of their involvement in therapy. The use of the six steps of the CA approach seemed to better patients understanding of their condition and their role in addressing their healthcare. As a result, it might be noted that the use of the ADL questionnaire may not be the best outcome measure during patient intake to assess patient needs for activities of daily living, and for patient goal creation.

Additionally, patients who received CA were more consistent with post discharge continuation of their home exercise programs by a large margin. These findings could be explained by better patient education and use of a specific learning model. Because of patient education, the patient had greater understanding of why they were in therapy and the purpose of the exercises they were given. Greater knowledge may help patients feel more empowered and motivated to continue with their home exercises. Several patients gave extremely positive feedback about how the amount of time spent with their therapist and the teaching style improved how they felt about their therapy. These patients indicated their patient visits were more beneficial because they knew how to take care of themselves better than any previous therapy visit or visits to their healthcare provider. One patient stated that "because there was so much emphasis on correct home exercise, I felt confident that I was exercising correctly and would not re-injure myself. This made it easy to perform my home program."

Although this study was unique in that is used patients in the role as students and physical therapists as the teachers, the results coincide with published literature. Specifically, that the use of $\mathrm{CA}$ as a teaching and learning model is effective in the learning process to assist learners in a 
structured environment. And provides a significant pathway for students to follow, and for those who teach to guide and direct learning in an effective way. The results of this study also reconfirm the importance of proper patient education in healthcare empowering patients with the ability to understand and affect their condition by direct involvement. This was chiefly shown by patient continued use and performance of home exercises after discharge from skilled therapy services.

One disappointment from the study was the lack of impact on traditional outcome measures of disability ratings, ADL independence, pain, and self-efficacy which did not occur when compared to the control group. One reason for this finding might be explained by the skill and quality of the therapists providing treatment of the control group as they have excellent clinical skills and were able to match general outcomes as measured by instruments in this study when compare with the treatment group. Additionally, this might be explained by the time frame of the study and the collection of data, if the post test results were gathered several weeks after discharge a statistically different result may have been found. Of the patients who were in the study almost all showed improvement in their condition, lowering of pain ratings, improved outcomes overall on measures used to a satisfactory level. Both patients and physicians were generally pleased with patient overall progress and outcomes from receiving therapy.

Limitations of the Study: The age differences in population which were statistically significant between the treatment group and the control group and both groups were predominantly White. Because age is not an important factor, these results could be generalized to patient populations without significant concerns. This study was limited using convenience sampling and not randomization of subjects in the study. Also, the treatment group therapists and both groups of patients were not blinded to the study. This type of study would be difficult to 
blind patients as the goal is to actively involve them in learning and their education about their health and therapy. Due to the sampling of this study which was somewhat limited by the demographics of the populations of the two groups which identified a younger population in the treatment group with several subjects currently in the role of student as they were attending a local university.

The sheer amount of information to be gathered as part of the study quickly became problematic for some patients. It took patients over 30 minutes to complete all the intake measures associated with the study. This new paperwork combined with normal patient intake data and evaluation exceeded the ideal amount of time for a first therapy session. To accommodate patients and manage time, the data intake was split up into two sessions. Patients were given the knowledge test and functional outcome measure associated with their condition on the date of evaluation and the remaining tests were given on visit two before use of the CA was initiated. Patient feedback was positive and more patients were willing to continue participation in the study with this accommodation.

Potentially the selection of outcome measurement tools lacked sensitivity to measure changes in patients over such a short timeframe. Perhaps future study could look at use of these outcome measures six months after patient discharge to assess significance of the use of CA over a longer period of time with these outcome measures. This may be difficult in actual clinical practice as patients who are discharged from skilled therapy may not be readily available for follow up six months after discharge, and population numbers may be more difficult to achieve. Loss of patients in the study was of some concern however the nature of the study allowed for uninhibited participation choice by the patient and was respected throughout the data collection process. 
A difficulty we faced was overcoming the preconceived experiences of therapy or healthcare in general. Many individuals noted that it was the responsibility of the healthcare provider to get them better and that their role was limited. This attitude of dependency could have been a factor in explaining why self-efficacy scores were not significantly different. After completion of the study, many in the treatment group were able and willing to accept a primary role in their wellness, a few persisted that it was the job of the provider to fix them and they were not responsible at all for their health and wellness. These patients presented a particular challenge that unfortunately use of the CA did not make a significant difference for these patients.

Another challenge was a patient who would not learn how to use the pain scale properly. No matter how much teaching occurred, one patient never understood the term "No Pain", and during their treatment never rated lower than a 6/10, and frequently rated her pain at a 12 or higher even though 10 is the maximum on the scale. She was highly functional and pain did not limit her activity.

Therapist instruction and training in the treatment group were provided over a four-week training period with use of technicians, and student volunteers as mock patients. Modeling and feedback using CA were provided by the principal investigator until the therapist performed the steps consistently. The therapists involved in the study found the CA form of instruction/teaching easy to follow and quickly engaged the patients. The therapists needed more training to develop the CA skills of reflection and exploration in comparison to the other CA skills.

From a clinical perspective, the primary difficulty faced during the study was therapists slipping back into prior teaching strategies and habits either of non-teaching or poorly directed teaching. The therapists required continued mentoring and attention to the use of CA as a teaching model throughout the study.

Quick reference cards were provided for the therapist with the six steps of CA and sample of each step available for reference as needed. Staff meetings were held weekly as a format to continue improvement in teaching skill, resolve concerns and answer questions 
therapists had about technique, and application. Weekly training meetings on CA were vital to the success of the program. Therapists shared concerns, experiences, and examples. There were opportunities in these meetings for reflection, practice modeling, coaching, and scaffolding to occur. The consistent meetings helped the therapists develop the use of CA as part of their therapy skill set.

One implication from this study was that physical therapy education programs could provide better models for patient education during the student's academic experience so that good teaching habits are formed at the same time treatment, and examination skills are developed. This process would undoubtedly improve the overall patient care provided by therapists when they enter professional practice.

This study adds to the evidence based research on patient education that will aid in establishing best practices and could reduce the cost of healthcare to the patient and society. Use of CA related to patient education could be incorporated into the curriculum of health care professionals at the graduate and post-graduate level. Using CA could improve healthcare practitioner's confidence to successfully provide meaningful patient education. Documented patient improvements could lead to changes in reimbursement for patient education, making it more practical for professional therapist to spend time on better patient education using a model such as CA.

Discussion: CA provides a framework for operation when trying to share and communicate information to others. It became apparent that the CA model for patient education was also effective for instruction and training the therapists who provided the treatments in the clinic. The therapists began using the steps of CA in training meetings to improve their skills of using CA for patient education. CA was valuable as a tool to teach student therapists and assistants their assignments in the clinic. As an administrator, communication and instruction using CA has made a difference in working with staff and employees. Use of the CA has become an integral part of our facility. The clarity that use of this model provides has become more apparent the longer we have actively worked to implement it into our practice. 
Patients for the most part quickly grasped onto this model and were enthusiastic about the learning model. CA empowered them to take better care of themselves and they progressed from passive participants to active contributors to their rehabilitation experience. As patients learned how to solve problems on their own, they made better choices with their activities outside the clinic environment and were eager to report how they had taken better care of themselves. Their consistency with home exercises improved and lasted well beyond discharge from skilled therapy.

Recommendations: Post discharge surveys indicated the patients educated through CA were continuing their home exercise plan. It would have been beneficial to include outcome measures such as the DASH at the four-week post discharge instead of at the time of discharge, to see if the increased time performing the home exercises would have also improved the outcome measure scores in comparison with the control group. Other recommendations may include: Random assignment to multiple clinics within the same city using multiple clinicians within the same vicinity; use of only 3-4 outcome measures to decrease time for intake; phone survey follow-ups at six-months post discharge, and looking at other ways to measure patient compliance with therapy recommendations.

Future Studies: There are three suggested areas in physical therapy that have been researched but have not been studied using the CA framework. First, look at insurance demographics and compare use of the CA for patient education. Does the type of insurance, coverage and copays and who was paying for the service matter in whether individuals are empowered to become more in control over their healthcare? Would the use of CA motivate patients to be involved without regard to the payment source? The Dolot et al. study (2015) concludes that insurance coverage does indeed affect choices to participate in therapy.

A second area of investigation and research would be to study CA as a learning/teaching model in the professions of physical and occupational therapy for clinical patient education in comparison with another learning/teaching model such as "Blended learning" or "Problem-Based Learning". Multiple studies have investigated the use of Problem based learning or PBL in 
therapy curriculums for student education (Castro-Sanchez, Encarnacion, Aguilar-Ferrandiz, Mataran-Penarrocha, Iglesias-Alonso, Fernandez-Fernandez, Moreno-Lorenzo 2012; Williams, MacDermid, Wessel, 2003). Comparison of PBL to CA would identify effectiveness of these teaching models clinically and assist in pursuing an ideal model for patient instruction and education.

Third, another potential direction for future study would be the use of CA in conjunction with technology using resources such as you-tube videos and guided activities that disseminate information to patients with online quizzes that can be repeated. This could be combined with online monitoring of the patient exercise programs. Patients log into the system daily and record the results of their exercise or check the completion of their daily HEP routines. The Knight et al. study (2015) demonstrates the positive effects technology can have on patient therapy and its success. Perhaps, adding some form of motivation such as a discount on the final bill for participation in the online exercise log could be initiated as part of the study.

Finally, further study could create a pathway for use of the CA in graduate education models to teach student therapists a model for patient education. Patient education enables patients to better care for themselves and future therapists will be more successful if they follow a framework for helping their patients learn how to be responsible for their own healthcare. The study of CA in these areas would further our knowledge in the rehabilitation sciences and provide for better patient outcomes and contribute to "best practices" enhancing professional growth for the provider and improve the quality of patient care. 


\section{APPENDIX A}

6 MINUTE WALK TEST

Date:

Patient Name:

Beg Vitals: BP $H R$ 02 \% EKG -

Assistive Device Used:

\# of Laps Completed: \# of Breaks Taken:

Overall Distance Completed: $\mathrm{ft}$

(111 ft per lap) (Normal averages)

$\begin{array}{llll}60-69 \mathrm{M} & 1755 \mathrm{ft} & 80-89 \mathrm{M} & 1209 \mathrm{ft} \\ 60-69 \mathrm{~F} & 1547 \mathrm{ft} & 80-89 \mathrm{~F} & 1104 \mathrm{ft} \\ 70-79 \mathrm{M} & 1643.4 \mathrm{ft} & 90-101 \mathrm{M} & 971 \mathrm{ft} \\ 70-79 \mathrm{~F} & 1438 \mathrm{ft} & 90-101 \mathrm{~F} & 856 \mathrm{ft}\end{array}$

End Vitals: BP $H R$ 02 \% EKG -

ATS statement: guidelines for the six-minute walk test. Table 1.(2002). American Journal of Respiratory \& Critical Care Medicine, 166(1), 111-117. 


\section{APPENDIX B}

TABLE 15-37

Activities of Daily Living Questionnaire

\begin{tabular}{|c|c|c|c|}
\hline Activity & No difficulty & $\begin{array}{c}\text { Some } \\
\text { difficulty }\end{array}$ & $\begin{array}{l}\text { Cannot } \\
\text { perform }\end{array}$ \\
\hline $\begin{array}{l}\text { Self-care, Personal Hyg } \\
\text { Urinating } \\
\text { Defecating } \\
\text { Brushing teeth } \\
\text { Combing hair } \\
\text { Bathing } \\
\text { Dressing } \\
\text { Eating }\end{array}$ & & & \\
\hline $\begin{array}{l}\text { Communication } \\
\text { Writing } \\
\text { Typing } \\
\text { Seeing } \\
\text { Hearing } \\
\text { Speaking } \\
\text { Physical Activity } \\
\text { Standing } \\
\text { Sitting } \\
\text { Reclining } \\
\text { Walking } \\
\text { Climbing stairs } \\
\end{array}$ & & & \\
\hline $\begin{array}{l}\text { Sensory Function } \\
\text { Hearing } \\
\text { Seeing } \\
\text { Tactile feeling } \\
\text { Tasting } \\
\text { Smelling }\end{array}$ & & & \\
\hline $\begin{array}{l}\text { Nonspecialized Hand A } \\
\text { Grasping } \\
\text { Lifting } \\
\text { Tactile discrimination }\end{array}$ & & & \\
\hline $\begin{array}{l}\text { Sexual Function } \\
\text { Orgasm } \\
\text { Ejaculation } \\
\text { Lubrication } \\
\text { Erection }\end{array}$ & & & \\
\hline Sleep, Restful Pattern & & & \\
\hline
\end{tabular}

Rondinelli, Robert D. (2008). Activities of daily living questionnaire. In Guide to the Evaluation of Permanent Impairment 6th Ed. Chicago, Illinois. The American Medical Association 


\section{APPENDIX C}

\section{Lower Limb Questionnaire}

Instructions

Please answer the following questions for the lower limb being treated or followed up. If it is BOTH lower limbs, please answer the questions for your worse side. All questions are about how you have felt, on average, during the past week. If you are being treated for an injury that happened less than one week ago, please answer for the period since your injury.

1. During the past week, how stiff was your lower limb? (Circle one response.)
1 Not at all
2 Mildy
3 Moderately
4 Very
5 Extremely

2. During the past week, how swollen was your lower limb? (Circle one response.)
1 Not at all
2 Mildly
3 Moderately
4 Very
5 Extremely

During the past week, please tell us about how painful your lower limb was during the following activities. (Circle ONE response on each line that best describes your average ability.)

\begin{tabular}{lccccccc} 
& $\begin{array}{c}\text { Not } \\
\text { painful }\end{array}$ & $\begin{array}{c}\text { Mildly } \\
\text { painful }\end{array}$ & $\begin{array}{c}\text { Moderately } \\
\text { painful }\end{array}$ & $\begin{array}{c}\text { Very } \\
\text { painful }\end{array}$ & $\begin{array}{c}\text { Extremely } \\
\text { painful }\end{array}$ & $\begin{array}{c}\text { Could not } \\
\text { do because } \\
\text { of lower } \\
\text { limb pain }\end{array}$ & $\begin{array}{c}\text { Could not } \\
\text { do for other } \\
\text { reasons }\end{array}$ \\
3. Walking on flat surfaces? & 1 & 2 & 3 & 4 & 5 & 6 & 7 \\
\hline 4. Going up or down stairs? & 1 & 2 & 3 & 4 & 5 & 6 & 7 \\
\hline 5. Lying in bed at night? & 1 & 2 & 3 & 4 & 5 & 6 & 7
\end{tabular}

6. Which of the following statements best describes your ability to get around most of the time during the past week? (Circle one response.)
1 I did not need support or assistance at all.
2 I mostly walked without support or assistance.
3 I mostly used one cane or crutch to help me get around.
4 I mostly use two canes, two crutches or a walker to help me get around.
5 I used a wheelchair.
6 I mostly used other supports or someone else had to help me get around.
7 I was unable to get around at all.

7. How difficult was it for you to put on or take off socks/stockings during the past week? (Circle one response.)

1 Not at all difficult 2 A little bit difficult 3 Moderately difficult 4 Very difficult 5 Extremely difficult 6 Cannot do it at all

Rondinelli, Robert D. (2008). The Upper Extremities. In Guide to the Evaluation of

Permanent Impairment 6th Ed. (pp. 555). Chicago, Illinois. The American Medical Association. 


\section{APPENDIX D}

\section{NeCK DisabiLITY InDEX}

THIS QUESTIONNAIRE IS DESIGNED TO HELP US BETTER UNDERSTAND HOW YOUR NECK PAIN AFFECTS YOUR ABILTTY TO MANAGE EVERYDAY - LIFE ACTIVITIES. PLEASE MARK IN EACH SECTION THE ONE BOX THAT APPLES TO YOU. ALTHOUGH YOU MAY CONSIDER THAT TWO OF THE STATEMENTS IN ANY ONE SECTION RELATE TO YOU, PLEASE MARK THE BOX THAT MOST CLOSELY DESCRIBES YOUR PRESENT -DAY SITUATION.

\section{SECTION 1 - PAIN INTENSITY}

I have no pain at the moment.

The pain is very mild at the moment.

The pain is moderate at the moment.

a The pain is fairly severe at the moment.

a The pain is very severe at the moment.

The pain is the worst imaginable at the moment.

\section{SECTION 2 - PERSONAL CARE}

ㄱ I can look after myself normally without causing extra pain.

I can look after myself normally, but it causes extra pain.

It is painful to look after myself, and $I$ am slow and careful.

I need some help but manage most of my personal care.

I need help every day in most aspects of self -care.

I do not get dressed. I wash with difficulty and stay in bed.

\section{SECTION 3 - LIFTING}

ㅁ I can lift heavy weights without causing extra pain.

I can lift heavy weights, but it gives me extra pain.

a Pain prevents me from lifting heavy weights off the floor but $I$ can manage if items are conveniently positioned, ie. on a table.

a Pain prevents me from lifting heavy weights, but I can manage light weights if they are conveniently positioned.

I can lift only very light weights.

I cannot lift or carry anything at all.

\section{SECTION 4 - WORK}

․ I can do as much work as I want.

․ I can only do my usual work, but no more.

- I can do most of my usual work, but no more.

I can't do my usual work.

I can hardly do any work at all.

I can't do any work at all.

\section{SECTION 5 - HEADACHES}

․ I have no headaches at all.

․ I have slight headaches that come infrequently.

I I have moderate headaches that come infrequently.

a I have moderate headaches that come frequently.

ㅁ I have severe headaches that come frequently.

․ I have headaches almost all the time.

\section{SECTION 6 - CONCENTRATION}

․ I can concentrate fully without difficulty.

I can concentrate fully without difficuity.

I can concentrate fuily degree of difficulty concentrating.

I have a fair degree of difficulty concent

I have a lot of difficulty concentrating.

I I have a great deal of difficul

\section{SECTION 7 - SLEEPING}

ㅁ I have no trouble sleeping.

My sleep is slightly disturbed for less than 1 hour.

My sleep is mildly disturbed for up to 1-2 hours.

- My sleep is moderately disturbed for up to 2-3 hours.

- My sleep is greatly disturbed for up to 3-5 hours.

My sleep is completely disturbed for up to 5-7 hours.

\section{SECTION 8 - DRIVING}

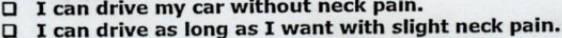

I can drive as long as I want with moderate neck pain.

I can't drive as long as I want because of moderate neck pain.

I can hardly drive at all because of severe neck pain.

I can't drive my care at all because of neck pain.

\section{SECTION 9- READING}

I can read as much as I want with no neck pain.

I can read as much as I want with slight neck pain.

I can read as much as I want with moderate neck pain.

- I can't read as much as I want because of moderate neck pain.

․ I can't read as much as I want because of severe neck pain.

口 I can't read at all.

\section{SECTION 10 - RECREATION}

ㅁ I have no neck pain during all recreational activities.

I have some neck pain with all recreational activities. I have some neck pain with a few recreational activities. - I have neck pain with most recreational activities.

- I can hardly do recreational activities due to neck pain.

I can't do any recreational activities due to neck pain.
PATIENT NAME

SCORE

[50]
DATE

BENCHMARK $-5=$

Vernon, H., Mior, S. (1991). The Neck Disability Index: A study of reliability and validity. Journal of Manipulative Physiological Therapeutics, 14, 409-415. 


\section{APPENDIX E}

Patient Name: Date:

Instructions: These questions ask for your views about how your pain now affects how you function in everyday activities. Please answer every question and mark the ONE number on EACH scale that best describes how you feel.

1. Does your pain interfere with your normal work inside and outside the home? Work normally
Unable to work at all

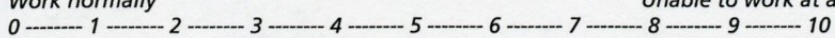

2. Does your pain interfere with personal care (such as washing, dressing, etc.)? Take care of myself completely Need help with all my personal care

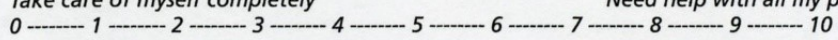

3. Does your pain interfere with your traveling? Travel anywhere I like
$0-1$ -

4. Does your pain affect your ability to sit or stand? No problems Cannot sit / stand at all

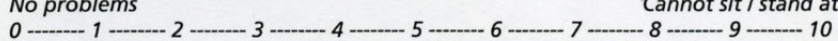

5. Does your pain affect your ability to lift overhead, grasp objects, or reach for things? No problems
0

6. Does your pain affect your ability to lift objects off the floor, bend, stoop, or squat? No problems Cannot do at all

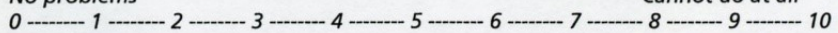

7. Does your pain affect your ability to walk or run? No problems
0

8. Has your income declined since your pain began? No decline 20 Lost all income 10

9. Do you have to take pain medication every day to control your pain? No medication needed 3 On pain medication throughout the day

10. Does your pain force you to see doctors much more often than before your pain began? Never see doctors
0

11. Does your pain interfere with your ability to see the people who are important to you as much as you would like? No problem
0 No problem
0

12. Does your pain interfere with recreational activities and hobbies that are important to you? No interference Total interference

13. Do you need the help of your family and friends to complete everyday tasks (including both work outside the home and housework) because of your pain? Never need help Need help all the time Never need help
0

14. Do you now feel more depressed, tense, or anxious than before your pain began? No depression / tension Severe depression / tension 0 - 10

15. Are there emotional problems caused by your pain that interfere with your family, social, and / or work activities? No problems
$0-1-3-5$

Anagnostics, C., Gatchel, R.J., \& Mayer, T.G. (2004). The Pain Disability Questionnaire:

A New Psychometrically Sound Measure for Chronic Musculoskeletal Disorders. Spine, 29(20), 
La actividad fisica regular es divertida y saludable, y más personas cada dia están comenzando a ser más activas. Ser más activo es seguro para la mayoria de las personas. Sin embargo, algunos individuos deben consultar a un médico antes de iniciar un programa actividad fisica.

Si usted planifica involucrarte en más actividades físicas de los que está ahora, responda a las siete preguntas de los recuadros más abajo. Si usted tiene entre 15 a 69 años de edad, el cuestionario PAR-Q le indicará si necesita consultar a su médico antes de iniciar un programa de ejercicio 0 actividad fisica. Si usted tiene más de 69 años de edad, y no esta acostumbrado a estar activo, acuda a su médico.

El sentido común es la principal guia para contestar a estas preguntas. Favor de leer las preguntas con cuidado y responder cada una honestamente; marque SI o NO.

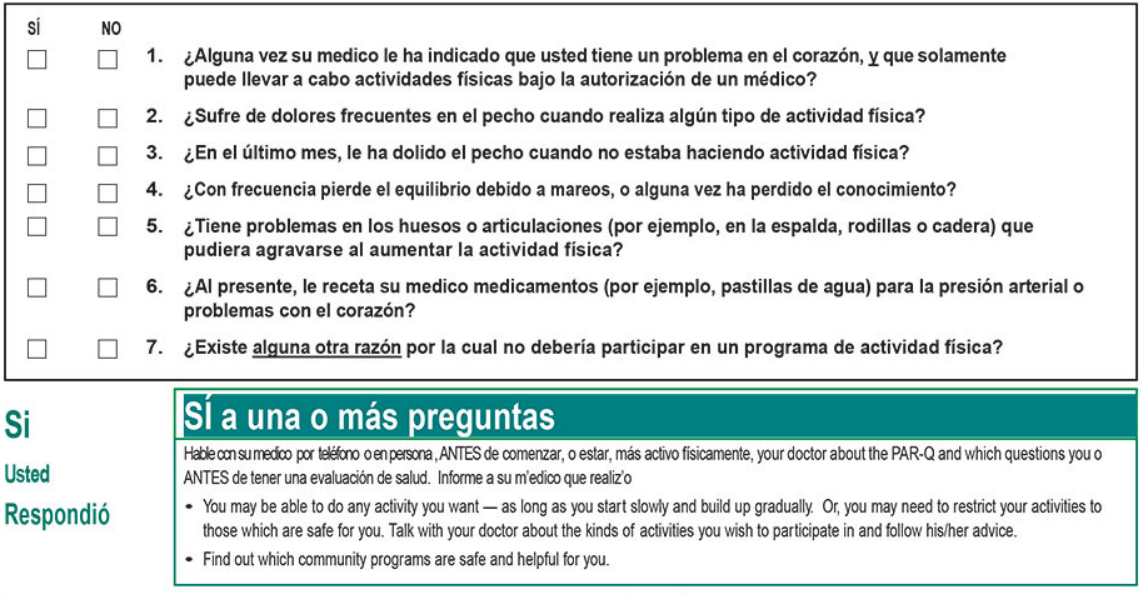

\section{NO to all questions \\ If you answered NO honestly to all PAR-Q questions, you can be reasonably sure that you can: - start becoming much more physically active - begin slowly and build up gradually. This is the safest and easiest way to go \\ - take part in a fitness appraisal - this is an excellent way to determine your basic fitness so that you can plan the best way for you to live actively. It is also highly recommended that you have your blood pressure evaluated. If your reading is over 144/94, talk with your doctor before you start becoming much more physically active.}

DELAY BECOMING MUCH MORE ACTIVE: - if you are not feeling well because of a temporary illness such as a cold or a fever - wait until you feel better; or - if you are or may be pregnant - talk to your doctor before you start becoming more active.

Informed Use of the PAR-Q: The Canadian Society for Exercise Physiology, Heath Canada, and their agents assume no liability for persons who undertake physical activity, and if in doubt after completing this questionnaire, consult your doctor prior to physical activity.

No changes permitted. You are encouraged to photocopy the PAR-Q but only if you use the entire form.
NOTE: If the PAR-Q is being given to a person before he or she participates in a physical activity program or a fitness appraisal, this section may be used for legal or administrative purposes.
"I have read, understood and completed this questionnaire. Any questions I had were answered to my full satisfaction."
SIGMUTURE___
WINES

Nota: Este cuestionario es válido para un máximo de 12 meses a partir de la fecha en que se completa y se convierta en inválido si su problema de salud cambia, de manera que deberia contestar SI a cualquiera de las siete preguntas.

Canadian Society for Exercise Physiology. (2002). Physical Activity Readiness.

\section{Questionnaire-PAR-Q. retrieved from http:/www.csep.ca/forms.}




\section{APPENDIX $\mathbf{G}$ page 1}

\section{QuickDASH}

Please rate your ability to do the following activities in the last week by circling the number below the appropriate response.

\begin{tabular}{|c|c|c|c|c|c|c|}
\hline & \\
\hline & & $\begin{array}{c}\text { NO } \\
\text { DIFFICULTY }\end{array}$ & $\begin{array}{c}\text { MILD } \\
\text { DIFFICULTY }\end{array}$ & $\begin{array}{l}\text { MODERATE } \\
\text { DIFFICULTY }\end{array}$ & $\begin{array}{c}\text { SEVERE } \\
\text { DIFFICULTY }\end{array}$ & UNABLE \\
\hline 1. & Open a tight or new jar. & 1 & 2 & 3 & 4 & 5 \\
\hline 2. & Do heavy household chores (e.g., wash walls, floors). & 1 & 2 & 3 & 4 & 5 \\
\hline 3. & Carry a shopping bag or briefcase. & 1 & 2 & 3 & 4 & 5 \\
\hline 4. & Wash your back. & 1 & 2 & 3 & 4 & 5 \\
\hline 5. & Use a knife to cut food. & 1 & 2 & 3 & 4 & 5 \\
\hline 6. & $\begin{array}{l}\text { Recreational activities in which you take some force } \\
\text { or impact through your arm, shoulder or hand } \\
\text { (e.g., golf, hammering, tennis, etc.). }\end{array}$ & 1 & 2 & 3 & 4 & 5 \\
\hline
\end{tabular}

\begin{tabular}{|c|c|c|c|c|c|}
\hline & NOT AT ALL & SLIGHTLY & MODERATELY & $\begin{array}{l}\text { QUITE } \\
\text { A BIT }\end{array}$ & EXTREMELY \\
\hline \multirow[t]{2}{*}{$\begin{array}{l}\text { 7. During the past week, to what extent has your } \\
\text { arm, shoulder or hand problem interfered with } \\
\text { your normal social activities with family, friends, } \\
\text { neighbours or groups? }\end{array}$} & 1 & 2 & 3 & 4 & 5 \\
\hline & $\begin{array}{l}\text { NOT LIMITED } \\
\text { AT ALL }\end{array}$ & $\begin{array}{l}\text { SLIGHTLY } \\
\text { LIMITED }\end{array}$ & $\begin{array}{l}\text { MODERATELY } \\
\text { LIMITED }\end{array}$ & $\begin{array}{l}\text { VERY } \\
\text { LIMITED }\end{array}$ & UNABLE \\
\hline $\begin{array}{l}\text { 8. During the past week, were you limited in your } \\
\text { work or other regular daily activities as a result } \\
\text { of your arm, shoulder or hand problem? }\end{array}$ & 1 & 2 & 3 & 4 & 5 \\
\hline $\begin{array}{l}\text { Please rate the severity of the following symptoms } \\
\text { in the last week. (circle number) }\end{array}$ & NONE & MILD & MODERATE & SEVERE & EXTREME \\
\hline 9. Arm, shoulder or hand pain. & 1 & 2 & 3 & 4 & 5 \\
\hline \multirow[t]{2}{*}{$\begin{array}{l}\text { 10. Tingling (pins and needles) in your arm, } \\
\text { shoulder or hand. }\end{array}$} & 1 & 2 & 3 & 4 & 5 \\
\hline & $\begin{array}{l}\text { NO } \\
\text { DIFFICULTY }\end{array}$ & $\begin{array}{l}\text { MILD } \\
\text { DIFFICULTY }\end{array}$ & $\begin{array}{l}\text { MODERATE } \\
\text { DIFFICULTY }\end{array}$ & $\begin{array}{l}\text { SEVERE } \\
\text { DIFFICULTY }\end{array}$ & $\begin{array}{l}\text { SO MUCH } \\
\text { DIFFICULTY } \\
\text { THAT I } \\
\text { CAN'T SLEEP }\end{array}$ \\
\hline $\begin{array}{l}\text { 11. During the past week, how much difficulty have } \\
\text { you had sleeping because of the pain in your arm, } \\
\text { shoulder or hand? (circle number) }\end{array}$ & 1 & 2 & 3 & 4 & 5 \\
\hline
\end{tabular}

QuickDASH DISABILITY/SYMPTOM SCORE $=\left(\left[\frac{(\text { sum of } n \text { responses })}{n}\right]-1\right) \times 25$, where $n$ is equal to the number
of completed responses.

A QuickDASH score may not be calculated if there is greater than 1 missing item.

Retrieved from columkbiaspine.org/wp-content/uploads/2016/01/Shoulder2c_Elbow2c_Wrist_Hand.pdf 


\section{APPENDIX G page 2}

\section{QuickDASH}

\begin{tabular}{|c|c|c|c|c|c|}
\hline \multicolumn{6}{|c|}{$\begin{array}{l}\text { WORK MODULE (OPTIONAL) } \\
\text { The following questions ask about the impact of your arm, shoulder or hand problem on your ability to work (induding } \\
\text { homemaking if that is your main work role). }\end{array}$} \\
\hline \multicolumn{6}{|c|}{$\begin{array}{l}\text { Please indicate what your job/work is: } \\
\supset \text { । do not work. (You may skip this section.) } \\
\text { Please circle the number that best describes your physical ability in the past week. }\end{array}$} \\
\hline Did you have any difficulty: & $\begin{array}{c}\text { NO } \\
\text { DIFFICULTY }\end{array}$ & $\begin{array}{c}\text { MILD } \\
\text { DIFFICULTY }\end{array}$ & $\begin{array}{l}\text { MODERATE } \\
\text { DIFFICULTY }\end{array}$ & $\begin{array}{c}\text { SEVERE } \\
\text { DIFFICULTY }\end{array}$ & UNABLE \\
\hline 1. using your usual technique for your work? & 1 & 2 & 3 & 4 & 5 \\
\hline $\begin{array}{l}\text { 2. doing your usual work because of arm, } \\
\text { shoulder or hand pain? }\end{array}$ & 1 & 2 & 3 & 4 & 5 \\
\hline 3. doing your work as well as you would like? & 1 & 2 & 3 & 4 & 5 \\
\hline 4. spending your usual amount of time doing your work? & 1 & 2 & 3 & 4 & 5 \\
\hline
\end{tabular}

\section{SPORTS/PERFORMING ARTS MODULE (OPTIONAL)}

The following questions relate to the impact of your arm, shoulder or hand problem on playing your musical instrument or sport or both. If you play more than one sport or instrument (or play both), please answer with respect to that activity which is most important to you.

Please indicate the sport or instrument which is most important to you:

D I do not play a sport or an instrument. (You may skip this section.)

Please circle the number that best describes your physical ability in the past week.

\begin{tabular}{|c|c|c|c|c|c|}
\hline Did you have any difficulty: & $\begin{array}{c}\text { NO } \\
\text { DIFFICULTY }\end{array}$ & $\begin{array}{l}\text { MILD } \\
\text { DIFFICULTY }\end{array}$ & $\begin{array}{l}\text { MODERATE } \\
\text { DIFFICULTY }\end{array}$ & $\begin{array}{l}\text { SEVERE } \\
\text { DIFFICULTY }\end{array}$ & UNABLE \\
\hline $\begin{array}{l}\text { 1. using your usual technique for playing your } \\
\text { instrument or sport? }\end{array}$ & 1 & 2 & 3 & 4 & 5 \\
\hline $\begin{array}{l}\text { 2. playing your musical instrument or sport because } \\
\text { of arm, shoulder or hand pain? }\end{array}$ & 1 & 2 & 3 & 4 & 5 \\
\hline $\begin{array}{l}\text { 3. playing your musical instrument or sport } \\
\text { as well as you would like? }\end{array}$ & 1 & 2 & 3 & 4 & 5 \\
\hline $\begin{array}{l}\text { 4. spending your usual amount of time } \\
\text { practising or playing your instrument or sport? }\end{array}$ & 1 & 2 & 3 & 4 & 5 \\
\hline
\end{tabular}

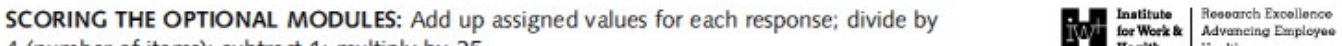
4 (number of items); subtract 1; multiply by 25.

An optional module score may not be calculated if there are any missing items. OINSTIUTE FOR WORK \& HENTTH 2006 . ALL RUCHTS RESERVED

Retrieved from columkbiaspine.org/wp-content/uploads/2016/01/Shoulder2c_Elbow2c_Wrist_Hand.pdf 


\title{
APPENDIX H
}

\section{Oaweatry Dlagbillty Questlonnalre}

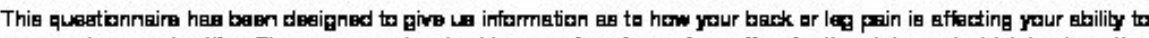

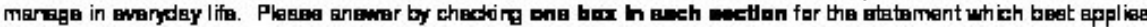

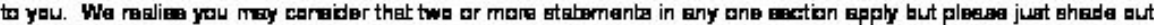

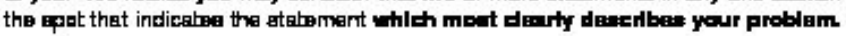

\section{Bextan 1: Pun Intensity}

$\square$ I have re paln at the marnent

$\square$ The priln le very milld at the mankent

$\square$ The poin la medergte at the mement

$\square$ The praln le felrly aevere at the mankert

$\square$ The pal n la wery aevere at the mannert

$\square$ The poin la the warat Imegingble gt the marnert

gextlan 2: Personal care (ed. wishing, dris:ing]

口 I Egn lexk efter myolf narrnelly withaut eaualng extre $\mathrm{pH} n$

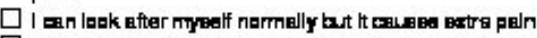

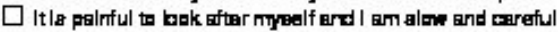

$\square$ I need aeme help but can menape megt of my pereangl mine

$\square$ I need halp ewery day In mast aspects of aelfare

$\square$ I de rot pet dreased, magh with diffleulty ard atry In bed

gestinn 3: Ufthg

$\square$ I tean llft heavy weighte witheut extre paln

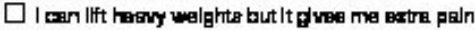

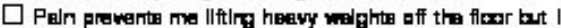
cin mangeg if they are anmeriently placad eg. an a thele

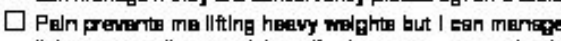
llght to medlurn walghts if ther gre cenwanlertily paltiened

$\square$ I tain anly llft wery llghtwalghta

$\square$ I Eannet lfft ar crarty anything

\section{gextion 4: Whking*}

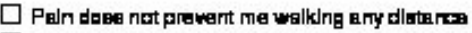

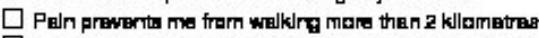

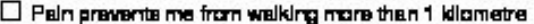

$\square$ Paln prevertite me from walking mere then 500 metrea

$\square$ I gan anlywalk ualng a gatek ar endtehes

$\square$ I am in bed meat of the t/me

\section{Bectian 5: altting}

$\square$ I ann alt In Bny ehalr es bng ar I llke

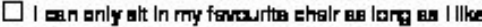

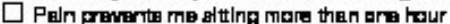

$\square$ Paln prevertita me fram altting mare then 30 minutee

$\square$ Peln prevertita me fram eltting mare then 10 minutee

$\square$ Peln preventa me fram alttro et El

\section{Bextinn 6: 8tanding}

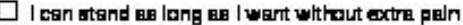

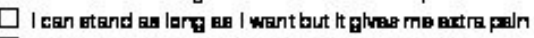

$\square$ Peln prevente me fram atand ng far mere than 1 heur

$\square$ Peln prewents me fram gotending for mare then 30 minutee

$\square$ Peln prewents me fram gotending for mare then 10 mintites

$\square$ Paln prevants me fram atandlng at all

\section{Bextion 7: glesping}

$\square$ hty adeap la never dlaturtad by paln

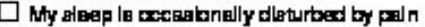

$\square$ Bextuas of prin I have lees then 6 houra aleep

$\square$ Eexrabe of praln I have lees then 4 lecura aleep

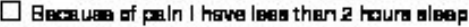

$\square$ PBln prewents me fram alegping at all

\section{Section 8: 8ex பfe (if applkuble)}

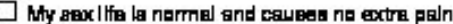

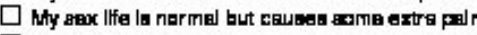

$\square$ hty aes llfe la nearly rarmil but la very falmitul

$\square$ Mhr aex llfe la amerely reatricted by peln

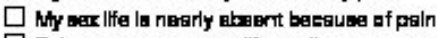

$\square$ Pin prewertit Ery bex lffe at al

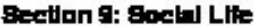

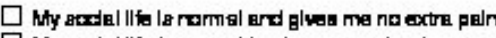

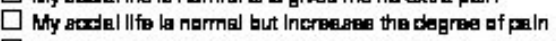

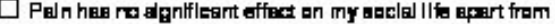
IIrnithig my mark energatle Interests e.g. aprort

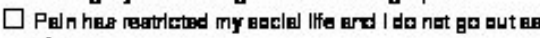
oftarn

$\square$ Peln hes rectrleted my atrelel llfe to my hame

$\square$ I have ra ageled Iffe becegues of paln

\section{Bection 10: Trarelling}

$\square$ I Egn tronel anywhere witlout paln

$\square$ I ean trang: anywhere but lt ghree ne extre paln

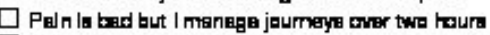

$\square$ Paln regtreta me to jeumeja of leeg then one tour

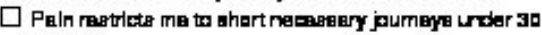
minutee

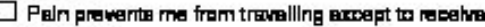
treatrient

Fairbank, J., \& Pysent, P. (2000). The Oswestry Disabliity Index. Spine, 25(22), 2910- 


\section{APPENDIX I}

\section{Self-efficacy For Exercise (SEE) Scale}

How confident are you right now that you could exercise three times per week for 20 minutes if:

\begin{tabular}{|l|c|c|c|c|c|c|c|c|c|c|c|}
\hline & \multicolumn{3}{|c|}{ Not Confident } \\
\hline $\begin{array}{l}\text { 1. The weather was } \\
\text { bothering you }\end{array}$ & 0 & 1 & 2 & 3 & 4 & 5 & 6 & 7 & 8 & 9 & 10 \\
\hline $\begin{array}{l}\text { 2. You were bored by } \\
\text { the program or activity }\end{array}$ & 0 & 1 & 2 & 3 & 4 & 5 & 6 & 7 & 8 & 9 & 10 \\
\hline $\begin{array}{l}\text { 3. You felt pain when } \\
\text { exercising }\end{array}$ & 0 & 1 & 2 & 3 & 4 & 5 & 6 & 7 & 8 & 9 & 10 \\
\hline $\begin{array}{l}\text { 4. You had to exercise } \\
\text { alone }\end{array}$ & 0 & 1 & 2 & 3 & 4 & 5 & 6 & 7 & 8 & 9 & 10 \\
\hline $\begin{array}{l}\text { 5. You did not enjoy it } \\
\text { 6. You were too busy } \\
\text { with other activities }\end{array}$ & 0 & 1 & 2 & 3 & 4 & 5 & 6 & 7 & 8 & 9 & 10 \\
\hline 7. You felt tired & 0 & 1 & 2 & 3 & 4 & 5 & 6 & 7 & 8 & 9 & 10 \\
\hline 8. You felt stressed & 0 & 1 & 2 & 3 & 4 & 5 & 6 & 7 & 8 & 9 & 10 \\
\hline 9. You felt depressed & 0 & 1 & 2 & 3 & 4 & 5 & 6 & 7 & 8 & 9 & 10 \\
\hline
\end{tabular}

\section{Self-Efficacy for Exercise (SEE) Scale}

About: This scale is a self-report of exercise self-efficacy.

Items: 9

Reliability: Internal consistency $=0.92$.

Validity: Mental and physical health scores on the SF-12 predicted efficacy expectations as measured by the SEE Scale. Furthermore, SEE efficacy expectations predicted exercise.

\section{Scoring:}

Total score is calculated by summing the responses to each question. This scale has a range of total scores from 0-90. A higher score indicates higher self-efficacy for exercise.

Resnick, B., \& Jenkins, L.S. (2000). Testing the Reliability and Validity of the SelfEfficacy for Exercise Scale. Nursing Research. 49. 


\section{APPENDIX J}

\section{Patient-Specific Functional Scale}

\section{Instructions:}

Please list 3 activities that you are UNABLE to do or have moderate to extreme difficulty doing as a result of your injury or pain level For each of the activities that you list, RATE the level of difficulty you have performing each activity using 0-10 scale listed below. On the 0-10 scale, the HIGHER the number, the EASIER yon can perform the activity. The LOWER the number, the more DIFFICULTY you have.

(Example: Dressing, sleeping, work duties, climbing stairs, etc.)

Patient-specific activity scoring scheme (Pick one number):

$0=$ Unable to perform activity $10=$ Able to perform activity at same level as before injury or problem

\begin{tabular}{|l|l|l|l|l|l|l|l|l|l|l|l|}
\hline Activity & 0 & 1 & 2 & 3 & 4 & 5 & 6 & 7 & 8 & 9 & 10 \\
\hline 1. & & & & & & & & & & & \\
\hline 2. & & & & & & & & & & & \\
\hline 3. & & & & & & & & & & & \\
\hline
\end{tabular}

\section{(Therapist will score)}

Total score-sum of the activity scores/number of activities Minimum detectable change $(90 \% \mathrm{Cl})$ for average score $=2$ points Minimum detectable change $(90 \% \mathrm{C})$ for single activity score 33 points

Stratford, P., Gill, C., Westaway, M. \& Brinkley, J. (1995). Assessing disability and change on the individual patients: a report of a patient specific measure. Physiotherapy Canada, 47, 258-263. 


\section{APPENDIX K}

Patient Education Assessment: Pre and Post Test

1. Accurately describe the pain scale. Write the numbers to the pain description.
A. No pain
B. Tolerable pain
C. Moderate pain
D. Excruciating pain

2. Physical Therapists are musculoskeletal experts who (fill in the blank).
A. teach patients how to properly stretch and exercise
B. correct mechanical dysfunctions through joint manipulation
C. can give medications for pain
D. A and B
E. all of the above

\section{Home exercise programs are a guide for when I want to exercise.}
A. True
B. False

4. Swelling is a message from my body telling me something is wrong.
A. True
B. False

5. Immediately after an injury and for the first $\mathbf{4 8}$ hours I should (fill in the blank).
A. apply heat
B. apply ice
C. alternate heat and ice
D. apply heat or ice whichever feels better 
6. Inflammation is the result of injury to body tissue. During the inflammation stage I should (fill in the blank).

A. get complete rest and not use the inflamed area

B. protect the injured area by limiting use within pain free range of motion

C. keep moving the area to maintain good motion and encourage blood flow

7. Explain your condition or prognosis.

8. I can return to previous activities when (describe conditions)

9. These are four exercises I can perform to improve my condition.
A.
B.
C.
D.

10. These are two examples of "pacing myself" during activities of daily living.
A.
B.

11. Who is responsible for getting me better?
A. My physician
B. My therapist
C. Myself
D. All of the above 
12. Which of the following apply if I am carrying around extra body weight?
A. I have an increased risk for injury
B. I am more likely to have decreased flexibility.
C. I may have increased blood pressure which is the leading cause of strokes.
D. I an increased have an increased risk for high cholesterol.
E. I have risk for high blood sugar and heart disease.

13. Warming up exercises for my muscles will reduce the chance of injury.
A. True
B. False

14. When lifting, I should (fill in the blank).
A. keep my body aligned
B. lift with my legs
C. bend at the low back
D. All of the above
E. A and B
F. None of the above

\section{Describe what a physical or occupational therapists does}

16. Describe the purpose of a home exercise program.

17. Doing too much (over-doing it) while my body is healing will result in

18. The difference between pain and soreness is 
19. Which of the following is not a sign of inflammation:
A. Swelling
B. Pain
C. Redness
D. Decreased range of motion or function
E. The skin becomes lighter when I push on it

20. How long should I wait before putting heat on an injury?
A. No need to wait, I can apply heat immediately
B. Wait 24 hours and watch for signs of pain and swelling.
C. Wait 48 hours and watch for signs of pain and swelling.
D. Wait 10 days and watch for signs of pain and swelling. 
References

American Academy of Pediatrics. (2003). Policy statement for the prevention of pediatric overweight and obesity. Pediatrics, 112 (2), 424-430.

American Physical Therapy Association. (2013). Vision statement for the physical therapy profession and guiding principles to achieve the vision. Retrieved from http://www.apta.org/Vision/

American Physical Therapy Association. (2014). The Guide to Physical Therapist Practice. $3^{\text {rd }}$ edition. Physical Therapy. Retrieved from http:/www.guidetoptpractice.apta.org

Assal, J.P., Albeanu, A., Peter-Riesch, B., Vaucher, J. (1993). Cost of training a diabetes mellitus patient. Effects on the prevention of amputation [Abstract]. Diabetes \& Metabolism, 19, 491-5.

Backus, C., Gulick, L. (2016). Accelerated leadership development via immersive learning and cognitive apprenticeship. International Journal of Training and Development, 14(2), 144148. doi: $10.1111 / \mathrm{j} .468-2419.2010 .00347 . x$

Bandura, A. (1999). Social cognitive theory: An agentic perspective. Asian Journal of Social Psychology, 2, 21-41.

Bartlett, E.E. (1985). Editorial. At last, a definition. Patient Education and Counseling, 7(4) 323324. Doi: 10.1016/0738-3991(85)90041-2

Bates, F.M., Dolce, J.N., Waynore, W.R. (2012). The cognitive apprenticeship model: Implications for its use in psychiatric rehabilitation provider training. Journal of Rehabilitation, 78(1), 5-10.

Beed, P. L., Hawkins, E.M., Roller, C.M.(1991). Moving learners toward independence: The power of scaffolding instruction. The Reading Teacher, 44(9), 648-655.

Beurskens, A.J.H.M., de Vet, H.C.W.., \& Koke, A.J.A. (1996). Responsiveness of functional status in low back pain: a comparison of different instruments. The Journal of Pain, 65,71-76.

Brand-Gruwel, S., Wopereis, I., Vermetten, Y. (2004). Information problem solving by experts and novices: Analysis of a complex cognitive skill. Computers in Human Behavior 21, 487-508. Retrieved from http://www. sciencedirect.com

Brown, A.L., Ash, D., Rutherford, M., Nakaguwa, K., Gordon, A., Campione, J.C. (1993). Distributed expertise in the classroom. In G. Saloman (Ed.), Distributed cognition: Psychological and educational considerations (pp. 188-228). Cambridge, England: Cambridge University Press.

Bruner, J.S. (1976). The process of education. Cambridge, US: Harvard University Press.

Castro-Sanchez, A.M., Encarnacion, M. Aguilar-Ferrandiz, M., Mataran-Penarrocha, G.G., Iglesias-Alonso, A.A., Fernandez, \& M.M., Moreno-Lorenzo, C.C. (2012). Problem based learning approaches to the technology education of physical therapy students. Medical Teacher, 34(1), e29-e45.doi:10.3109/0142159X.2012.638011.

Cattell, R.B. (1983). Structured personality learning theory-A wholistic multivariate research approach. Praeger Publishers. 
Chase, L. Elkins, J., Readninger, J., Shepard, K.F. (1993). Perceptions of Physical Therapists Toward Patient Education. Physical Therapy, 11, 787.

Collins, A. (1991). Cognitive apprenticeship and instructional technology. In. L. Idol \& B.F. Jones (Eds.), Educational values and cognitive instruction: Implications for reform, (pp.121-138). Hillsdale, NJ: Lawrence Erlbaum Associates, Inc.

Collins, A., Brown, J.S., \& Newman, S.E. (1987). Cognitive Apprenticeship: Teaching the craft of reading, writing, and mathematics. In: Resnick LB, ed. Knowing Learning, and Instruction: Essays in Honor of Robert Glaser. Hillsdale, NJ: Lawrence Erlbaum Associates 1989; 453-94.

Commission on Accreditation in Physical Therapy. (2014). Evaluative Criteria PT Programs. Retrieved from http://www.capteonline.org/AccreditationHandbook/.

Daley, L.K., Menke, E., Kirkpatrick, B., \& Sheets, D. (2008). Partners in Practice: A win-win model for clinical education. Journal of Nursing Education, 47(1), 30-32.

Dennen, V., Burner, K.J. (2008). The cognitive apprenticeship model in educational practice. In J.M. Spector, M.D. Merrill, J. Van Merrienboer, \& M.P. Driscoll (Eds.), Handbook of educational communications and technology, (pp. 425-439). Mahwah, NJ: Erlbaum.

Dolot, J., Viola, D., Qiuhu, S., \& Hyland, M. (2016). Impact of Out-of-Pocket Expenditure on Physical Therapy Utilization for Nonspecific Low Back Pain: Secondary Analysis of the Medical Expenditure Panel Survey Data. Physical Therapy, 96(2), 212-221. doi:10.2522/ptj.20150028.

Dunn, L.S. (2014). Occupational therapy level II fieldwork student perspectives of fieldwork education [Abstract]. Northern Kentucky University, 98.

Emmons, K., Rollnick, S. (2001). Motivational interviewing in health care settings: Opportunities and limitations. American Journal of Preventative Medicine, 20(1), 68-74. doi:10.1016/S0749-3797(00)00254-3

Farmer, J.A., Buckmaster, A., LeGrand, B. (1992). Cognitive apprenticeship: Implications for continuing professional education. New Directions for Adult \& Continuing Education, 55, 41-49.

Francom, G.M., Gardner, J. (2014). What is task-centered learning. TechTrends, 58,(5) 28-36.

Friberg, F., Granum, V., Bergh, A. (2012). Nurses' patient-education work: conditional factorsan integrative review. Journal of Nursing Management, 20(2), 170-186. doi:10.1111/j.1365-2834.2011.01367.x

Froiland, J.M. (2016) Motivational Interviewing. Salem Press Encyclopedia.

Grannis, C. (1981). The ideal physical therapist as perceived by the elderly patient. Physical Therapy, 61,479-486.

Heywood, A., Firman, D., Sanson-Fisher, R., Mudge, P., \& Ring I. (1996). Correlates of physician counseling associated with obesity and smoking. Preventative Medicine, 25, 268-276.

Hills, R., Kitchen, S.(2007). Satisfaction with outpatient physiotherapy: Focus groups to explore the views of patients with acute and chronic musculoskeletal conditions. Physiotherapy Theory and Practice, 23(1),1-20. 
Jarvela, S. (1995). The cognitive apprenticeship model in a technologically rich learning environment: interpreting the learning interaction. Learning and Instruction, 5, 237-259.

Jay, M., Gillespie, C., Schlair, S., Sherman, S., \& Kalet, A. (2010). Physicians' use of the 5As in counseling obese patients: is the quality of counseling associated with patients' motivation and intention to lose weight? BMC Health Services Research, 10,159. doi: 10.1186/1472-6963-10-159.

Jensen, G.M., Mostrom, E., (2013). Handbook of teaching and learning for physical therapists . $3^{\text {rd }}$ edition. St. Louis, Missouri: Elsevier.

Jumaat, N.F., Tasir, A. (2014). Instructional scaffolding in online learning environment: A metaanalysis. Research Gate, 74-77. Retrieved from https://www.researchgate.net/publicaton/269033099. doi:10.1109/LaTiCE.20145.22.

Kirschner, P.A. (1992). Epistemology, practical work and academic skills in science education. Science \& Education, 1, 273-299.

Knight, E., Werstine, R. J., Rasmussen-Pennington, D. M., Fitzsimmons, D., \& Petrella, R. J. (2015). Physical Therapy 2.0: Leveraging Social Media to Engage Patients in Rehabilitation and Health Promotion. Physical Therapy, 95(3), 389-396. doi:10.2522/ptj.20130432.

Lasley, J. (2016). Cognitive apprenticeship strategies in clinical education. Radiation Therapist, 25(1), 103.

Lave, J., Wenger, E. (1991). Situated learning: Legitimate peripheral participation. Cambridge: Cambridge University Press.

Lofald, D.R. (2013). Human Learning and Cognition. [Course Manual EDF6101/7150 Unit 11]. St. Augustine, Florida. University of St. Augustine. pp.246-289.

Lord, F. M. (1967). A paradox in the interpretation of group comparisons. Psychological bulletin, 68(5), 304.

May, B.J.(1983). Teaching. A skill in clinical practice. American Physical Therapy Association, 63(10), 1627-1633.

May, S. (2001). Patient Satisfaction with Management of Back Pain. Physiotherapy, 87(1), 4-20. doi:10.1016/S0031.9406(05)61186-8

McArdle, J. J. (2009). Latent variable modeling of differences and changes with longitudinal data. Annual review of psychology, 60, 577-605. doi:10.1146/annurev.psych.60.110707.163612.

McFarland, L. A., \& Ryan, A. M. (2006). Toward an integrated model of applicant faking.

Miner L. (2007). A field examination of current methods of teaching evidence-based practice to physical therapy students in professional programs [Abstract]. State University of New York. Albany, pp. 102.

Morris, D.M., Kitchen, E.M., \& Clark, D.E. (2009). Strategies for optimizing nutrition and weight reduction in physical therapy practice: The evidence. Physiotherapy Theory and Practice, 25(5-6), 408-423. doi:10.1080/09593980902835369.

Neff, Linda S. Lev Vygotsky and Social Learning Theories. Retrieved from jan.ucc.nau.edu/lsn/educator/edtech/learningtheorieswebsite/vygotsky.htm 
Nichol, J., Turner-Bisset, R. (2006). Cognitive apprenticeship and teachers' professional development. Journal of In-Service Education, 32(2), 149-169. doi:10.1080/13674580600650831.

Noone, J. (2009). Teaching to the three apprenticeships: Designing learning activities for professional practice in an undergraduate curriculum. Journal of Nursing Education, 48(8), 468-471.

Norman, D.A. (1991). Cognitive artifacts. In J.M. Carroll (ed), Designing interaction: Psychology at the human-computer interface (pp. 17-38). New York Cambridge University Press.

Page, C.G., Ross, I.A. (2004). Instructional strategies utilized by physical therapist clinical instructors: an exploratory study. Journal of Physical Therapy Education, 18(1),43-49.

Palinsar, A.S., Brown, A.L. (1984). Reciprocal teaching of comprehension-fostering and comprehension-monitoring activities. Cognition and Instruction, 1, 117-175.

Parsons, S., Harding, G., Breen, A., Foster, N., Pincus, T., Vogel, S., \& Underwood, M. (2007). The influence of patients' and primary care practitioners' beliefs and expectations about chronic musculoskeletal pain on the process of care: a systematic review of qualitative studies. Clinical Journal of Pain, 23(1), 91-98.

Patel, V.L., Branch, T., \& Arocha, J.F. (2002). Errors in interpreting quantities as procedures: The case of pharmaceutical labels. International Journal of Medical Informatics, 65, 193211. doi:10.1016/S1386-5056(02)00045-x

Pea, R.D. (2004). The social and technological dimensions of scaffolding and related theoretical concepts for learning, education, and human activity. Journal of the Learning Sciences, 13(3) 423-451. doi:10.1207/s15327809j1s1303 6.

Pignataro, R.M., Huddleston, J. (2015). The use of motivational interviewing in physical therapy education and practice: Empowering patients through effective self-management. Journal of Physical Therapy, 29(2), 62-71.

Puntambekar, S., Hubscher, R. (2005). Tools for scaffolding students in a complex learning environment: What we gained and what have we missed? Educational Psychologist, 40(1), 1-12.

Rindflesch, A. (2009) A grounded-theory investigation of patient education in physical therapy practice. Physiotherapy Theory and Practice, 25(3), 193-202.

Reise,r B.J. (2004). Scaffolding complex learning: The mechanisms of structuring and problematizing student work. Journal of the Learning Sciences, 13(3), 273-304.

Resnick, LB. (1987). The 1987 Presidential Address: Learning in school and out. Educational Researcher, 13-20.

Roosevelt, F.D. (2008). Zone of proximal development. Encyclopedia of Educational Psychology, SAGE publication.

Shabani, K., Khatib, M., Ebadi, S. (2010). Vygotsky's zone of proximal development: Instructional implications and teachers' professional development. Canadian Center of Science and Education, 3(4),237-245. 
Shimbo, T., Goto, M., Morimoto, T., Hira, K., Takemura, M., Matsui, K., . . Fukui, T. (2004). Association between patient education and health-related quality of life in patients with Parkinson's disease. Quality of Life Research, 13(1),81-89.

Shipman, J.P., Lake, E.W., Van De Volgen, J., \& Doman, D. (2016). Provider documentation of patient education: a lean investigation. Journal of Medical Library Association, 104(2), 154-158.

Singer, J. D., Willett, J. B., Singer, J. D., \& Willett, J. B. (2003). Doing data analysis with the multilevel model for change. Applied longitudinal data analysis: Modeling change and event occurrence, 96-97

Skelton, A., Murphy, E.A., Murphy, R.J.L., \& O'Dowd, T.C. (1995) Patient education for low back pain in general practice. Patient Education and Counseling, 25,329-334.

Skelton, A. (1998). The hidden curriculum of patient education for low back pain in general practice. Sociology of Health \& Illness, 20(1), 96-111.

Sluijs, E. (1991). A checklist to assess patient education in physical therapy practice: development and reliability. Physical Therapy, 71(8), 561-569.

Sotosky, J. (1984). Physical Therapists' Attitudes Toward Teaching. Physical Therapy, 64(3), 347-350.

Stalmeijer, R.E., Dolman,s D.H.J.M., Wolfhagen, I.H.A.P., \& Scherpbier, A.J.J.A. (2009). Cognitive apprenticeship in clinical practice: Can it stimulate learning in the students? Advances in Health Science Education, 14(4), 535-546.

Stalmeijer, R.E. (2015). When I say...cognitive apprenticeship. Medical Education, 49, 355-356. doi:10.1111/medu.12630.

Stribling, J.C., Richardson, J.E. (2016). Placing wireless tables in clinical settings for patient education. Journal of Medical Library Association, 104(2), 159-164.

Turner, S. Wellard, S., \& Bethune, E. (1999). Registered nurses' perceptions of teaching: Constraints to the teaching moment. International Journal of Nursing Practice, 5(1), 1420.

Van de pol, J., Volman, M., Beishuizen, J. (2010). Scaffolding in teacher-student interaction: A decade of research. Educucational Psychology Review, 22,271-296.

Vygotsky, L.S. (1956). The development of higher forms of attention in childhood. [collected psychological works]. Moscow. N.K. Krupskaya Academy of Communist Education.

Vygotsky, L.S. (1981). The genesis of higher mental functions. In J.V. Werrsch (Ed.), The Concept of Activity in Soviet Psychology, (pp. 163). Armonk, NY: Sharpe.

Vygotsky, L.S. (1997). The genesis of higher mental functions. In M.J. Hall et al., The Collected Works of L.S. Vygotsky. Plenum Press, New York.

Vygotsky, L.S. (1980). Mind in society: The development of higher psychological processes. Harvard University Press.

Williams, R., MacDermid, J., \& Wessel, J. (2003). Student adaptation to problem-based learning in an entry-level master's physical therapy program. Physiotherapy Theory \& Practice, 19(4), 199-212. Doi:10.1080/091593980390246715. 
Wood, D., Bruner, J.S., \& Ross, G. (1976). The role of tutoring in problem solving. Journal of Child Psychology and Psychiatry, 17, 89-100.

Wood, D., Wood, H., Middleton, D. (1978). An experimental evaluation of four face-to-face teaching strategies. International Journal of Behavioral Development, 1, 131-147.

World Health Organization (WHO) Regional Office for Europe Copenhagen. (1998).

Therapeutic Patient Education: Continuing Education Programmes for Health Care Providers in the Field of Prevention of Chronic Diseases (ISBN 928901298 6). Retrieved from http://www.euro.who.int/_ data/assets/pdf_file/0007/145294/E63674.pdf. 